Aus dem Laboratorium für allgemeine und pharmazeutische Chemie der Universitat Lausanne.

\title{
Beiträge zur Kenntnis der Fabiana imbricata Ruiz und Pavon (Pichi-Pichi) und ihrer chemischen Bestandteile.
}

\author{
Von Dozent Dr. Hermann Kunz-Krause.
}

(Eingegangen den 28. XI. 1898.)

Diese der südamerikanischen Flora angehörende Solanacee erschien zuin erstenmale im Jahre 1885 unter den Bezeichnungen Pichi, bezw. Pichi-Pichi ${ }^{1}$ ) in kleinen Mengen anf dem europäischen Markte. Die Droge, welche aus den beblätterten Zweigen, untermischt mit düneren Aststïcken bestand, gelangte damals zu keiner weiteren Beachtung und verschwand in den darauffolgenden Jahren infolge Mangels auch wieder völlig vom Markte. Spätere, durch die Herren Parke, $\mathrm{D}$ avis \& $\mathrm{Co}$. in Detroit (Michigan) an Ort und Stelle veranlasste Nachforschungen ${ }^{2}$ ) ermöglichten neue Einsammlungen, sodass dieselbe seit ca. 5 Jahren sowohl als solche, wie auch besonders in Form des Fluid-Extraktes Aufnahme in die Preisverzeichnisse der europäischen Drogenhäuser gefunden hat. ${ }^{8}$ )

Eine von den Herren Parke, Davis \& Co. im Jahre 1886 an die medizinische Fakultät der Universităt Leipzig gesandte erste Probe der Rohdroge gab mir schon damals Gelegenheit zu einer orientierenden Voruntersuchung, deren Resultate durch die Prüfung des Extr. fluid. und Extr. spissum - welche beiden Präparate mir später, nebst zweier

1) Die Verdoppelung des Namens ist eine in den südamerikanischen Dialekten - und auch im spanischen Idiom - häufig zu beobachtende Erscheinung. So heisst $\mathfrak{u}$. a. der in Südamerika weit verbreitete Kibitz (Vanellus cayanensis L.) im Arankanischen: Tehuel-Tehuél und ăhnlich im Spanischen: Terru-terro. (s. R. Martin, Altpatagonische Schädel, Vierteljahrsschrift der Naturforsch.-Ges. Zürich, 41, (1896), Jubelband, S. 525.) Auch das im franzosischen Idiom za "Quinquina" gewordene $Q$ uina-Quina gehört hierher.

2) The Pharmacology of the Never materia medica. George S. Davis, Detroit, 1889, p. 1065.

8) Gehe \& Co., Handelsber. Sept. 1893, S. 31. E. Merck, Berirht uber das Jahr 1893, Januar 1894, S. 50. 
grösseler Posten der Droge in entgegenkommenster Weise vou 1 gleichen Hause zur Verfügung gestellt wurden und wofür ich Herren Parke, Davis \& $\mathrm{C}_{0}$, auch an dieser Stelle meinen D ausspreche - kontrolliert und ergänzt werden konnten.

Der ganz aussergewöhnliche Charakter und Habitus dieser Solana mag es entschuldigen, wenn ich im folgenden zunächst etwas nă auf die botanischen Verhältnisse dieser Pflanze eingehe.

Die der Familie der Solanaceae, Unterfamilie, Nicotian (Fabianeae nach Lyons) angehörende Gattung Fabiana ist, wie die in Frage kommende Art Fabiana imbricata schon seit langem beka

C. H. Pearsoon ${ }^{1}$ giebt bereits folgende prägnante Beschreibung

Fabiana: corolla infundibuliformis, limbo plicato, revoluto. Tu longissimus. Stamina inaequalia. Stigma emarginatum. Capsula bilocula bivalvis.

F. imbricata (Ruiz und Pavon): Foliis imbricatis, ovatis, mini Habitat in regni chilensis campis et ripis arenosis. Resinosa. Tamar habitu. Frutex. (Flora Perur. 2. p. t. XII, 122.)

Nach den Angaben von $\left.R u^{3 b} y^{3}\right)$ und von $0 \operatorname{chsenius}^{8}$ ) kommt d: Art zwischen dem $29-37^{\circ} \mathrm{s}$. Br. und in $300-2000 \mathrm{~m}$ Meereshöhe in trocke Gegenden Chilis vor.4) Das Holz des gewöhnlich nur $1 \mathrm{~m}$ hohen, verein: - z. B. bei Elqui in der Provinz Coquimbo - bis zu $4 \mathrm{~m}$ erreichenc hellblaugrünen, auf allen zarteren Teilen mit einen wohlriechenden $\mathrm{Ha}$ bedeckten Halbstranches findet als solches technische Verwendung zur. fertigung kleinerer Schnitzarbeiten, wie Löffel u. a. m. Mit dem Absad c selben - Aleadia genannt - sollen von alters her die Arauco-India 1 and in neuerer Zeit auch amerikanische Aerzte bei Eiterungen der Xie und der Blase, wie auch des Magens und der Lunge ausserordentlich gïnst Erfolge erzielt haben. Auch gegen Blasenstein und Syphilis soll "Aleadin"(?) mit gutem Erfolg angewandt worden sein.5) Sicher ist. d die Blätter und dünnen $Z$ weige in Südamerika schon seit langem als Mi gegen den das Klauenvieh - besonders Ziegen und Schafe - heimsuchen Leb eregel (Distoma hepaticum) gebraucht werden. ${ }^{6}$ ) Das die obenerwäh erste Sendung der Droge (aus dem Jahre 1886) begleitende Schreihen enth: folgende, auf den Gebrauch bezügliche Angaben:

1) Synopsis plantarum seu Énchiridium botanic. 1805 , t. I, p. 176.

2) Pharm. Rdsch. 1886, p. 64. Ref. Pharm. Zentralh. 27, (1886), p. 4

3) Archiv der Pharmazie 24, (1886), p. 896.

4) Die oben erwähnte Sendung der Herren Parke, Davis \& 1 bestand aus zwei Posten, von denen der eine als "Northern Pichi“, der and als "Southern Pichi" bezeichnet war.

5) Gehe \& Co. schreiben (1. c.) unter Extr. Pichi tiuid.: Jjieses sct halb vergessene Extrakt kam neuerdings wieder in Aufnahme. Dr. Fris länder findet es bei gewissen Erkrankungen des Harnapparates, speziell ? akuter Gonorrhoe und Cystitis sehr wirksam.

6) Ochsenius, 1. c. 
„Die Stämmchen und (beblätterten) Zweige des Strauches werden klein geschnitten und solange mit Wasser gekocht, bis dieses eine violette Farbe ${ }^{1}$ ) angenommen hat. Der Kranke darf bei dem Genuss des nicht unangenehmen Thees 2) leichte Speisen und Getränke jeder Art geniessen und hat nur geistiger Getränke sich zu enthalten."

Der Habitus des Strauches erinnert an denjenigen der Cupressineae (Thuja-Arten) und einzelner Ericaceae ${ }^{8}$ ). Die Zweige stehen dicht gedrängt an den Aesten, mit kleinen Deckblättchen an der Insertionsstelle versehen. Die Ansatzstellen der Zweige bleiben an den Aesten als weisse, deutlich hervortretende Narbenwülste lange sichtbar. Die Rinde hängt dem gelbweissen, dichten Holze fest an. Die dünneren Zweige sind von dunklerer Farbe als die älteren. Die Verzweigung ist eine unregelmässige - teils wirtelige, teils abwechselnde - Dichotomie. Die Richtung der Zweige ist eine meist einseitswendige und rasch aufstrebende. Aeltere Aeste und St und ist seicht längsrissig. Die Droge besitat einen schwach-harzig-balsamischen Geruch und aromatisch-bitteren Geschmack. Sie ist sehr harzreich.

Die Blätter sind mit breiter Basis sitzend, dicht gedrängt in enger Spirale um die Achse gestellt. Sie decken sich gegenseitig dachziegelförmig (F. imbricata) ca. bis zu ihrer halben Höhe. Das einzelne Blatt ist nadelförmig, kurz und klein, lanzettlich zugespitzt, kahnförmig, mit konvexer Aussen- (Unter-) und konkaver Innen- (Ober-) Seite, mit deutlichem Kiel anf der Rückenfläche. An der inneren Anhaftungsstelle der Blätter beobachtet man meist ein reichliches harziges Exsudat in Form einer weissen, amorphen, durchscheinenden und glasglänzenden Masse. Dasselbe findet sich überdies anch an fast allen jüngeren Zweigen und Aestchen vor (s. u. "Fabianaresen “).

Die in der Droge vereinzelt noch sich vorfindenden Blüten und Blütenteile, als auch Früchte gestatten die Feststellung der für die SolanaceaeNicotianeae typischen Charaktere. Die Blüten brechen einzeln aus den Enden einseitswendiger, bis $z u \quad 1,5 \mathrm{~cm}$ langer $Z$ weige hervor, diese als Terminalknospen abschliessend. Die blütentragenden Zweige stehen in den Achseln etwas grösser als die übrigen Laubblätter entwickelter, im übrigen jedoch diesen aequivalenter Laubblätter, welche durch den hervorbrechenden Zweig etwas zur Seite gedrängt sind.

Die Blüte ist klein, mit dem Kelche nur 10-12, höchstens bis $20 \mathrm{~mm}$ lang. Letzterer ist bleibend, monosepal, fünfzipfelig, mit deutlich hervor-

1) Der violette Farbenton der hellbraunen Abkochung wird durch die Gegenwart des weiterhin beschriebenen 4-Oxy-, 5-Methoxy-Cumarols (Chrysatropasäure) bedingt.

2) Die Droge - und ebenso der wässerige Absud der Blätter besitzt einen aromatischen Geruch und eigentümlich bitteren Geschmack. Die alkoholische Tinktur, welche, nebenher bemerkt, beim Vermischen mit Wasser reichlich Harz abscheidet, ist dagegen durch einen eher unangenehm bitteren und lange anhaftenden Geschmack charakterisiert.

8) Ochseniu (1.c.) bezeichnet den Habitus der Fabiana imbricata als „Tamarisken-ähnlich, während der Blütezeit Erica-ähnlich“. 
tretenden Rippen auf dem Rücken der kurzeu, breit-eiförmigen Zipfél. Die Krone ist farblos (weiss) oder violett, monopetal, röhrig, unmittelbar über dem Kelche - in 1/s der Gesamtlänge - bedeutend eingeschnürt, nach oben blasig aufgetrieben. Am Schlund wiederum verengert, mit fünf stumpfeiförmigen Zipfeln. Bei der Fruchtreife löst sich die Krone vom Grunde des bleibenden Kelches ab, indem sie durch die sich vergrössernde oder öffnende Kapsel durch einen oder auch zwei Risse von der Basis aus gesprengt wird. Stamina fünf, ungleich lang, mit der Röhre verwachsen und ihr in deren verengertem Teile entspringend. Die gelb gefärbten Antheren sind koptig, zweifächerig, mit longitudinaler Dehiscenz, im oberen. bauchigen Teile der Röhre liegend. Griffel 1, fädelig, mit kopfiger Narbe. ein weniges über die Staubfäden emporragend. Frucht eine holzige, an der Basis vom bleibenden Kelche umgebene, zweispaltig - durch tiefe Mittelteilung der beiden Fruchtblätter jedoch scheinbar vierspaltig - aufspringende Kapsel. Die beiden F'ruchtblätter sind an der Berührungsfläche auf ein Viertel des Querdurchmessers der Kapsel nach innen umgebogen.

Samen hellbraun, glänzend, breit-eirund, mit netzförmig-grubiger Oberfläche. Rippen wellig, mit Drüsen besetzt. Gruben hellgelb gefärbt, rundlicheiförnnig.

Die mikroskopisch-pharmakognostische Untersuchung der I)roge lag ausserhalb des der vorliegenden Studie gesteckten Rahmens. Dieselbe kann hier umso eher übergangen werden, als diese Verhältnisse durch eine inzwischen erschienene Arbeit von Tichomirow und Koljol) klargestellt worden sind und demnach als bekannt vorausgesetzt werden dürfen. Es mag daher genügen, an dieser Stelle auf die genannte, sehr ausführliche Untersuchung zu verweisen.

Obgleich nun anch in chemischer Hinsicht die Droge ebentalls schon und zwar mebrfach Gegenstand der Untersuchung gewesen ist, so erschien trotzdem oder vielleicht richtiger gerade darum eine erneute systematische Untersuchung derselben geboten: einerseits wegen der zum Teil hinwichtlich der Gegenwart, bezw. Abwesenheit einzelner Pflanzenstoffe sich widersprechenden Angaben der verschiedenen Autoren und der selbst für die bereits isolierten Körper zur Zeit noch ausstehenden näheren Charakterisierung: andererseits aber auch wegen der in dieser Pflanze so prägnant zum Ausdruck kommenden, in pflanzenphysiologischer, wie phytochemischer Hinsicht gleich interessanten Verschmelzung der Charaktere zweier grosser Pflanzenfamilien: der Solanaceae und Coniferae! Als das Resultat eines vieltausendjährigen Kampfes zwischen der Erhaltung der nationalen, d. h. Familieneigentümlichkeiten und der durch den Kampf um die Existenz bedingten Anpassung tritt uns diese eigenartige Pflanze entgegen! Wie ihre Schicksalsgenossen, die wenigen verkrüppelten Koniferen, in den steinigen Einöden der chilenischen Cordillere, schützt sie sich durch eine entsprechende Umbildung ihrer Blätter in nadelförmige Blattorgane und einen alle ihre zarteren Teile bekleidenden Harzüberzug gegen den Verlust ihres kleinen Wasservorrates

1) Pharm. Zeitschr. für Russl. 1891, pag. 673. Ref. Pharm. Post 25, 1892, pag. 110. 
wăhrend der langen Periode der Dürve dieser Regionen. Trotz dieser äusserlichen Differenzierung und trotz des Mangels eines, der Mehrzahl ihrer Verwandten eigentümlichen, Alkaloides, hat sie ibre spezifischen Familienqharaktere beibehalten, und zwar nicht allein in botanischer Hinsicht, sondern auch, und was mir ganz besonders bemerkenswert erscheint, hinsichtlich der von ihr erzeugten Pflanzenstoffe: die für verschiedene Arten der Gattung Atropa charakteristische C hrysa tropas äure findet sich auch in der Fabiana imbricata wieder!

Die folgende kurze Zu-ammenstellung der Untersuchungsresultate früherer Forscher diene zum Bcieg für das Gesagte und zur Orientierung über den derzeitigen Stand unserer chemischen Kenntnis dieser Pflanze.

Als Erster beschäftigte sich meines Wissens Rodriguez ${ }^{1}$ - veranlasat durch seine mit der Droge gemachten günstigen klinischen Erfahrungen bei funktionellen Störungen der Leber und des Harnapparates -mit der chemischen Untersuchung der Fabiana imbricata. Fr fand einen „krystallisierenden und fluorescierenden, dew Aesculin, bezw. Fraxin (l'aviin) ähnlichen" Körper, ein Harz und ein ätherisches Oel.

$\mathrm{Zu}$ denselben Resultaten gelangte kurze Zeit später Ly o $\mathbf{s}^{2}$ ), mit dem einzigen Unterschied, dass derselbe den fluorescierenden Körper, welchen Rodriguez ganz richtig als aesculinähnlich beschrieben hatte, irrtümlicherweise als "zum Teil wenigstens" mit diesem identisch bezeichnet. Ausserdem wies derselbe Autor die Gegenwart eines bitter schmeckenden, in Aether, Chloroform und Alkalien löstichen, in Wasser und Petroläther kauru löslichen Harzes nach und berichtet ferner über ein durch Behandeln der Droge mit ammoniakhaltigem Aether und Ausschütteln dieses ätherischen Auszuges mit saurem Wasser gewonnenes, bitter schmeckendes Alkaloid, welches krystallisierte Salze liefere (?). Wie ich weiterhin noch erörtern werde, scheint jedoch dieses, von L y on s bereits mit dem Namen „Fabianin“" belegte Alkaloid thatsächlich nichts anderes, als Cholin gewesen zu sein, welches ich in immerhin beträchtlichen Mengen aus der Droge isolieren konnte. Hierzu kommt noch, dass Ly ons die Gegenwart eines besonderen Alkaloids in der Hauptsache lediglich aus einigen, mit den allgemeinen Alkaloidreagentien in der vorerwähnten sauren wässerigen Lösung beobachteten Reaktionen ableitet.

Im darauf folgenden Jahre unterzogen dann $\mathrm{Nivière} \mathrm{und} \mathrm{Liotard}{ }^{3}$ ) - wohl durch die von Ly ons behauptete Gegenwart eines Alkaloids hierzu veranlasst - die Droge einer erneuten Untersuchung. Sie extrahierten dieselbe, nach dem Trocknen bei $110^{\circ}$, mit Schwefelkohlenstoff, bezw. mit Alkohol und Wasser, konnten jedoch in keinem der Auszüge ein Alkaloid nachweisen und schreiben daher die therapeutische Wirkung der Droge dem bereits aus den früheren Arbeiten bekannten fluorescierenden Körper zu,

1) Pharmaceutical Journ. (3) XV1, pag. 542. Ref. Pharmacology of the Newer Mat: med., bei George S. Davis, Detroit, pag. 1067. pag. 258.

2) Amer. Journ. of Pharm. 1886, pag. 65. Ref. Pharm. Zentralh. 1886,

8) Journ. de Pharm. et de Chim., V. Sér., 16 (1887), pag. 389. 
welchen sie aber für „ein dem Aeskulin verwandtes Glykosid“ halten. Diese Untersuchung zielte augenscheinlich nur auf den Nachweis des Alkaloides ah.

Wesentlich neue Momente in der pharmakochemischen Kenntinis der Fabiana imbricata brachten dann die Untersuchungen von G. A. Deitz, bezw. die an diese letzteren anschliessenden Arbeiten von Trimble and Schröter, und zwar besonders insofern, als wir in diesen Publikationen zum erstenmale ziffernmässigen Belegen begegnen! Ich kann mir nicht versagen, bei dieser Gelegenheit einmal offentlich und im allgemeinen auf die in wissenschaftlicher Hinsicht durchaus nicht zu unterschätzenden Nachteile summarischer Pflanzenuntersuchungen hinzuweisen, welche an die in der mineralogischen Praxis ïblichen und dort auch berechtigten sogen. Bauschanalysen erinnern! Machen sich für die Zwecke einer schnellen Orientierung derartige Untersuchungen notwendig, so sollte der Einführung eines neuen Namens, wo immer möglich, die Elementaranalyse, zum mindesten aber doch der sicher geführte Nachweis der Existenz des betreffenden Pflanzenstoffs vorausgehen! Die so häufig geübte Einführung neuer Namen für noch nicht analysierte, ja ihrer Existenz nach selbst noch fragliche Verbindungen bedingt nicht nur eine zwecklose Vermehrung unseres wissenschaftlichen Ballastes, sondern lähmt - infolge der Vorwegnahme der doch nur mit einer möglichst gründlichen Untersuchung verbundenen Berechtigung zur Namengebung - naturgemäss auch das Interesse späterer Forscher an dem Gegenstand!

(G. A. Deitz ${ }^{1}$ ) untersuchte die holzigen $Z_{\text {weige der Droge, indem er }}$ diese zunächst mit Petroläther und hierauf mit Aether erschöpfte. Das in einer Menge von 1,15\% gewonnene Petroläther-Extrakt bestand aus ätherischem Oel, Fett rom Schmp. 400, Wachs vom Schmp. $45^{\circ}$ und einem kautschukähnlichen Körper vom Schmp. $65^{\circ}$.

Dem in einer Menge von 1,41 $\%$ gewonnenen ätherischen Extrakt konnten durch heisses Wasser geringe Mengen eines ron Deitz als "Glykosid" bezeichncten, aus Aether in "sternförmigen Nestern" krystallisierenden Körpers entzogen werden, welcher aber voraussichtlich wiederam nichts anderes als die mehrerwähnte Chrysatropasäure war. Der in Wasser unIösliche, in Alkohol lösliche Teil bestand - nach den angegebenen Eigenschaften zu schliessen - aus dem weiterhin beschriebenen, krystallisierenden Fabianaresen, eine Annahme, welche auch durch die hier einsetzenden Untersuchungen von $\mathrm{Trimble}$ und $\mathrm{Schröter}{ }^{2}$ ) bestätigt wird (siehe unten: Fabianaresen).

Bemerkt sei noch, dass Deitz sowohl, wie Trimble und Schröter -- im Widerspruch mit Lyons und in Uebereinstimmung mit Nivière und Liotard - kein Alkaloid nachzuweisen vermochten.

1) Amer. Journ. of Pharm. 45 (1889), pag. 405. Ref. Chem.-Ztg. 1889, Rep. pag. 270 .

2) Amer. Journ. of Pharm. 45 (1889), pag. 407. Ref. Chem.-Ztg. 1889, Rep. pag. 270. 
Endlich berichtete Landenbeck ${ }^{1}$ ) nochmals über das Vorkommen eines krystallinischen, blan fluorescierenden Glykosides und eines bitteren Harzes in den Blättern der Fabiana imbricata und bestätigte damit lediglich einen Teil der Angaben früherer Forscher.

Uebergehend zur Mitteilung meiner eigenen Resultate sei vorausgeschickt, dass dieselben die zum Teil sich deckenden, zum Teil aber auch ergänzenden Ergebnisse von vier neben, bezw. nach einander ausgefuhrten Untersuchungsreihen darstellen, d. h. die Untersuchung erstreckte sich:

1. auf die Droge als solche, und zwar

A. auf die Blatter,

B. auf das fein gepulverte Holz;

2. auf das käufliche Extrakt, und zwar

C. auf das Fluid-Extrakt, und

D. auf das Extrakt. spissum.

Der in jedem einzelnen Falle beobachtete Arbeitsgang ist in Kürze folgender:

\section{Untersuchung der Droge.}

A. Untersuchung der Blätter.

Die gepulverten Blätter wurden einer dreifachen Extraktion unterworfen:

a) einer zweimaligen Extraktion mit heissem Wasser;

b) einer erschöpfenden Extraktion mit Aether in einem nach Soxhlet's System konstruierten Apparate;

c) einer Extraktion mit Alkohol.

a) Der wässerige, filtrierte Auszug ist dunkelbrann gefärbt, von stark bitterem Geschmack und ausgesprochen sauerer Reaktion, hingegen von nur geringem, aromatischem Geruche. Fehling'sche Lösung wird von ihm erst nach längerem Erhitzen zum Sieden und auch dann nur in geringem Grade reduziert. Werden dagegen die Blätter mit verdünnter Schwefelsăure mehrere Stunden zum Sieden erhitzt, so resultiert ein klares, rötlich gefarbbtes Filtrat, - von ausgesprochenem Geruch nach dem ätherischen Oel der Droge - welches alkalische Kupferlösung beim Erwărmen sofort reduziert. In gleicher Weise erlangt der vorerwähnte wăsserige Auszug die Reduktionsfähigkeit für Fehling'sche Lösung, unter gleichzeitigem Auftreten des angenehmen Geruchs nach dem ätherischen Oel, wenn derselbe mit verdünnter Schwefelsäure einige Zeit zum Sieden erhitzt wird. Der reduzierende Körper ist durch basisches Bleiacetat nicht fällbar: das durch Schwefelwasserstoff entbleite

1) Pharm. Post 1892, pag. 110. Ref. Pharm, Zentralh. 33 (1892). pag. 163. 
Filtrat vom Bleiniederschlage zeigt das gleiche Reduktionsvermögren für Fehling'sche Lösung, wie der ursprüngliche wăsserige Auszưg. Beim Neutralisieren mit Ammoniak nimmt dieser letztere eine grü nbraune Farbe und nach dem Uebersättigen mit Ammoniak die mehr erwähnte, schön blaue Fluorescenz an. Nach einiger Zeit entstand in der ammoniakalischen Flüssigkeit ein schön krystallinischer, weisser Niederschlag von Magnesium-Ammoniumphosphat. Nach nochmaliger Auflösung in verdünnter Essigsäure und Fällen mit Ammoniak wurde die Verbindung ein zweites Mal in der zur Lösung gerade hinreichenden Menge verdïnnter Essigsäure gelöst und diese Lösung unter eine Glocke neben Ammoniak gestellt. Nach kurzer Zeit beginnt die Ausscheidung schōn ausgebildeter Prismen und bald darauf ist die Lösung völlig salztrei, d. h. dieselbe giebt mit Ammoniak keinen Niederschlag mehr. Die Identität des derart erhaltenen Salzes mit Magnesium-Ammoniumphosphat ergab sich aus dem durch Titration mit Uranacetat ermittelten Phosphorsäuregehalte desselben:

Titer der Uranlösung: $1 \mathrm{ccm}=0,0055 \mathrm{P}_{2} \mathrm{O}_{5}$.

$0,10 \mathrm{~g}$ des Salzes, in Essigsäure gelöst, erforderten: $5,3 \mathrm{ccm}$ Uranlösung $=0,02915 \mathrm{~g} \mathrm{P}_{2} \mathrm{O}_{5}=29,15 \underset{10}{\alpha}$.

\section{Gefunden:}

Iroz. $\mathrm{P}_{2} \mathrm{O}_{5}$ : 29,15.
Berechnet für $\mathrm{Mg} \cdot \mathrm{NH}_{4} \cdot \mathrm{PO}_{4}=244,51$ : 28,98 .

Der damit erbrachte Nachweis der Gegenwart immerhin beträchtlicher Mengen Magnesiumphosphat in der Fabiana imbricata verdient Erwähnung und - in medizinischer Hinsicht - auch Beachtung! Der durch die Löslichkeit dieses Salzes in den Pflanzensäuren ermöglichte Uebergang desselben selbst in die wässerigen Abkochungen der Droge erklärt vielleicht - zum Teil wenigstens - die von verschiedenen Seiten bestätigten, günstigen Wirkungen derselben. Das ammoniakalische Filtrat vom Magnesium-Ammoniumphosphat-Niederschlage wurde hierauf mit Bleiessig ausgefällt. Aus dem Bleiniederschlage konnten - nach dem Zersetzen mit Schwefelwasserstoff - ausser den weiterhin zu beschreibenden beiden Verbindungen: Fabianatannoid und geringe Mengen Chrysatropasäure keinerlei greifbare Substanzen isoliert werden. Ebenso gab das ausgefällte und getrocknete Schwefelblei an heissen Alkohol lediglich Spuren der letztgenannten Verbindung ab.

In dem mit Schwefelwasserstoff entbleiten. Filtrate vom Bleiniederschlage konnte von Alkaloiden, obwohl dasselbe mit Quecksilberchlorid, Jod-Jodkalium und Tannin Fällungen gab, lediglich - durch Ausfällen mit Kalium-Mercurijodid, Zersetzen des schön zitrongelb gefärbten Mercurijodidniederschlages mit frischgefälltem Silberhydroxyd und Ueberführen der Base in das charakteristische Platindoppelsalz 
- Cholin nachgewiesen werden. Irgend ein anderes, spezifisches Alkaloid habe ich nicht auffinden können.

Ausserdem gab das Filtrat auch noch Fälingen mit Kupfer. sulfat und mit einer konzentrierten Lösung von Chlornatrium. Duruh dieses letztere Verhalten sind aber gewisse glykosidische Verbindungen, so u. a. nach Vulpius. ${ }^{1}$ ) die Condurango-Glykoside ansezeichnet.

Dies, wie auch das vorerwähnte differente Verhalten des wässerigen Auszuges gegen alkalische Kupferlösung vor und nach dt:m Erhitzen mit verdünnter Schwefelsäure schien sonach auch im vor ${ }^{-}$ liegenden Falle auf die Gegenwart eines Glykosides, bezw. eines glykosidischen Bitterstoffes hinzudeuten, als dessen, unter der Einwixkung der verdünnten Säure entstandene Spaltungsprodukte einesteils die, Fehling'sche Lösung reduzierende, Substanz und das ätherische Oel, anderenteils aber vielleicht auch der die Fluorescenz der alkalischen Lösung verursachende Körper aufgefasst werden durften. Der Versuch hat, wie ich glaube, diese Annahme bestätigt.

Der aus einem Teil des entbleiten Filtrates derart durch Chlornatrium gefällte, braune Niederschlag ist in Wasser, wie Ammoniak sehr leicht löslich und wird aus diesen Lösungen durch die geringste Menge verdünnter Schwefelsuure wieder pulverig ausgefällt. Der intensiv bitter schmeckenden wässerigen Lösung lässt sich der Körper durch Digerieren mit Tierkohle, und dieser letzteren, nach dem Trocknen, durch heissen Alkohol entziehen. Die alkoholische Lösung hinterlässt einen gelben, amorphen, in Wasser, Aether und Alkalien löslichen Rückstand. Wird dieser letztere init verulünter Schwefelsäure zum Sieden erbitzt, so entwickelt sich der charakteristische Geruch nach dem ätherischen Oel der Fabiana, die Flüssigkeit reduziert alkalische Kupferlösung und giebt an Aether einen gelblich getärbten Körper ab, welcher sich in Alkohol und Alkalien mit schön blauer Fluorescenz löst und als identisch mit Chrysatropasäure erkannt wurde!

Der Verdampfungsrückstand vom Filtrat der Chlornatriumfällung wurde ebenfalls mit Aether extrahiert. Dieser ätherische Auszug hinterliess eine braune, stechend riechende Flüssigkeit, deren Dämpfe Silbernitrat reduzierten, als dieselbe in offenem Gefässe neben eine wässerige Lösung dieses letzteren unter eine Glocke gestellt wurcle. Diese stechenden Dämpfe bestanden demnach voraussichtlich aus Ameisensäure.

Beim Vermischen dieser Flïssigkeit mit Wasser schied sich ein gelbliches Oel aus, welches alsbald zu einer fast farblosen, in Wasser wenig löslichen, plastischen und fadenziehenden Masse erstarite. Beim

1) Arch. d. Pharm. 283 (1885) pag. 299. 
Kochen mit verdünnter Schwefelsäure zeigte dieser Körper das gleiche Verhalten, wie der vorerwăhnte, durch Chlornatrium gefallte Niederschlag. Beide Substanzen waren sonach identisch. Nach dem Reinigen durch mehrmaliges Waschen mit Wasser, Wiederaufnehmen mit Aether und Verdunstenlassen der mit Chlorcalcium entwässerten, atherischen Lösung stellt dieser Körper einen aschefreien, hellgelben Balsam dar, der sich in viel siedendem Wasser zu einer goldgelben Flüssigkeit lobst und dieser wässerigen Lösung durch Aether wieder entzogen werden kann. Dieser gereinigte Körper wurde nun - zur weiteren Bestätigung der oben erwähnten Spaltung - in wässeriger Lösung, bezw: unter Zugabe einiger Tropfen verdtinnter Schwefelsăure, im Drackrohr während 6 Stunden auf $100^{\circ}$ erhitzt. Auch bei dieser Versuchsanordnung war - und zwar lediglich - in der mit Säure versetzten Lösung vollständige Spaltung in die drei oben genannten Komponenten eingetreten. Nachdem das mit Ammoniak alkalisierte Reaktionsprodukt durch Ausschütteln mit Chloroform vom gebildeten ätherischen Oele befreit war, konnte demselben - nach dem Ansäuern mit verdünnter Schwefelsäure - durch nochmaliges Ausschütteln mit Chloroform die Chrysatropasäure entzogen werden. Dieselbe wurde, nach dem Ver. dunsten des Lösungsmittels, in Nadeln erhalten und durch die weiterhin beschriebenen Reaktionen identifiziert. Als dritten Bestandteil enthielt die Reaktionsflüssigkeit ein alkalische Kupferlösung reduzierendes; nicht krystallisier'endes und optisch inaktives Spaltungsprodukt (Zucker ?).

Damit erscheint aber dieses "Weichharz" als die eigentliche Muttersubstanz der weiterhin beschriebenen Inhaltsstoffe der Fabiana imbricata: des Fabianols, bezw. des aus diesem entstehenden Fabianaresens und des Fabianatann oids, bezw. der vermutlich aus diesem durch weiteren Molekularzerfall hervorgehenden Verbindungen: des inaktiven Zu ckers und der Chrysatropasäure (siehe das Schema am Ende der Abhandlung).

Beim Erhitzen auf Platinblech verbrennt das Weichbarz unter Entwickelung des Geruches nach dem weiterhin beschriebenen Fabianaresen: ein fernerer Beweis für die Existenz genetischer Beziehungen zwischen diesen Körpern.

b) Der ätherische Auszug der Blätter stellte eine grünschwarze, weiche Masse dar, welche neben Chlorophyll das atherische Oel der Fabiana, das Fabianaresen und die Hauptmenge der Chrysatropasäure enthielt.

Zur Gewinnnng des Oeles wurde das Extrakt der Destillation im Dampfstrome unterworfen und dem wässerigen Destillat jenes durch Ausschütteln mit Aether entzogen. Die über Chlorcalcium getrocknete ätherische Lüsung hinterliess nach der Abtrennung des Aethers das 
Rohöl, welches sich durch fraktionierte Destillation im Wasserstoffstrome in einen in unbedeutender Menge darin enthaltenen, bei $130^{\circ}$ übergehenden Vorlauf und eine bei $\mathbf{2 7 5}^{\circ}$ übergehende Hauptfraktion trennen liess.

Diese letztere: das ätherische Oel der Fabiana imbricata, fur welches ich den Namen $\mathrm{Fabianol}$ vorschlagen möchte, bildet ein goldgelbes, angenehm kampfer- und krauseminz- bis majoranartig riechendes Oel. Es siedet bei $275^{\circ}$ (unkorr.) und färbt sich beim Erhitzen mit Kalilauge intensiv rot. Das Fabianol lässt sich - nebenher bemerkt - anch direkt aus den Blättern durch Destillation im Dampfstrom gewinnen.

0,5336 $\mathrm{g}$ mit Kupferoxyd im Sauerstoffstrome verbrannt, lieferten:

$$
\begin{aligned}
& 1,5825 \mathrm{~g} \mathrm{CO}_{2}=80,88 \% \mathrm{C} \text { und } \\
& 0,5558, \mathrm{H}_{2} \mathrm{O}=11,57, \mathrm{H} \text {. }
\end{aligned}
$$

Diese Prozentzahlen führen aber zu der Formel: $\mathrm{C}_{54} \mathrm{H}_{80} \mathrm{O}_{4}$.

$\begin{array}{ccc} & \text { Gefunden: } & \text { Berechnet für } \mathrm{C}_{\mathbf{S A}} \mathrm{H}_{20} \mathrm{O}_{4}: \\ \mathrm{C} & \mathbf{8 0 , 8 8} & 80,80 \\ \mathrm{H} & 11,57 & 11,20 .\end{array}$

Die refraktometrische Prüfung mittels des $A$ bb é 'schen Refraktometers ergab folgende Werte:

$$
\begin{gathered}
\mathrm{n}_{[\mathrm{D}]}=1,5076 \\
\mathrm{Z}=36,8 .
\end{gathered}
$$

Hieraus berechnet sich die Dispersion:

$$
\Delta_{\mathrm{n}}=0,0084 \text {. }
$$

Die Refraktion des Fabianols zeigt sonach eine bemerkenswerte Uebereinstimmung mit den von Marpmann ${ }^{1}$ ) ermittelten Werten folgender ätherischer Oele:

$$
\begin{aligned}
& \text { Ol. Balsam. Copaiv. rein: } n_{[D]}=1,5045 \\
& \text { "Calami } \quad=1,5075 \\
& \text { " Ligni Santali }
\end{aligned}
$$

a) westindischer Herkunft: $\quad, \quad=1,5080$

b) ostindischer $\quad, \quad=1,5076$.

Der vom Oel befreite Extraktrïckstand wurde in mässig starkem Alkohol heiss gelöst, diese heisse Lösung mit Ammoniak versetzt und hierauf solange mit Wasser verdünnt, bis eine abfiltrierte Probe durch weiteren Wasserzusatz nicht mehr gefallt wurde. Der Niederschlag bestand neben Chlorophyll aus dem weiterhin beschriebenen Fabianaresen. Das intensiv indigblau fluorescierende Filtrat wurde hierauf mit verdünnter Schwefelsäure angesäuert und wiederholt mit Chloroform ansgeschüttelt. Die vereinigten Chloroform-Auszuge hinterliessen

1) Pharm. Zentralh. 33, (1892), pag. 211. 
die Chrysatropasäure - als solche wurde die Substanz weiterhin erkannt - in Form einer zunächst noch bräunlich-gelb gefärbten Krystallmasse. Zur weiteren Reinigung warde dieselbe in wenig mit Natronlauge alkalisiertem Wasser gelöst und diese Lösung mit Gips zur Trockne gebracht. Das resultierende gelbliche Pulver wurde hierauf mit Wasser kalt extrahiert. die wässerige, filtrierte Lösung mit Schwefelsảure angesäuert und mit Aether extrahiert. Die ätherische Lösung hinterlässt nach dem Verdunsten die Chrysatropasäure in Form farbloser Nadeln.

Die Verbindung krystallisiert aus Alkobol in gelblichen und glänzenden, aus Chloroform hingegen in farb- und glanzlosen Prismen. Die Identität mit dem in der Familie der Solanaceae häufig vorkommenden und neuerdings von E. Schmidt ${ }^{1}$ ) auch mit der in Gelsemiurn sempervirens enthaltenen Gelseminsäure identifizierten 4-Oxy, 5-Methox ycumarol (Chrysatropasäure, $\beta$-Methyl-Aesculetin) ergab sich sowohl aus dem Schmelzpunkt $204^{\circ}$, wie aus den Resultaten der Elementaranalyse.

$0,2227 \mathrm{~g}$ der bei $100^{\circ}$ bis zum konstanten Gewicht getrockneten Substanz lieferten, mit Kupferoxyd im Sauerstoffstrome verbrannt:

\begin{tabular}{|c|c|}
\hline \multicolumn{2}{|c|}{$\begin{array}{l}0,5053 \mathrm{~g} \mathrm{CO}_{2}=61,88 \% \text { und } \\
0.0878, \mathrm{H}_{2} \mathrm{O}=4,38 . \mathrm{H} .\end{array}$} \\
\hline Gefunden: & Berechnet für $\mathrm{C}_{10} \mathrm{H}_{8} \mathrm{O}_{4}$ : \\
\hline 4,38 & 4,16 \\
\hline
\end{tabular}

Auch in seinem übrigen Verhaltelı stimmt der Körper durchaus mit der Chrysatropasäure überein. So löst er sich, wie diese, in Salpetersäure mit tief gelber Farbe, welche auf Zusatz von Ammoniak in blutrot übergeht und metallisches Natrium erzeugt in seiner absolut alkoholischen Lösung einen amorphen, hochgelb gefärbten Niederschlag einer bereits eingehends beschriebenen Natriumverbindung. ${ }^{2}$ ) Das von den früheren Beobachtern vermutete, Huorescierende Glykosid war sonach nichts anderes als Chrysatropasäure: ein Irrtum, der insofern entschuldbar ist, als auch das 4-Oxy -, 5-Methoxycumarol alkalische Kupferlösung beim Erwärmen wie ein Glykosid reduziert.

c) Das alkoholische Extrakt der Blätter stellte eine braune, extraktartige Masse dar, deren wässeriger Auszng alkalische Kupferlosung direkt nur langsam und nach längerem Kochen, sofort hingegen nach dem voraufgegangenen Erhitzen mit verdünnter Schwefelsäure reduziert. In der durch nochmaliges Lösen in Alkohol und Wieder. aufnehmen des Verdampfungsrückstandes dieser filtrierten alkoholischen

1) Archiv der Pharmazie 236, (1898), pag. 324.

2) H. Kunz-Krause, Archiv der Pharmazie 236, (1898), pag. 542. 
Lösung mit Wasser gewonnenen Lösung des Extraktes konnte lediglich Fabianagerbsäure (Fabianaglykotannoïd) und Cholin: ersteres durch Fallen mit basischem Bleiacetat als hochgelb gefarbte Bleiverbindnng, letzteres aus dem entbleiten Filtrate vom Bleiniederschlage darch Fallen mit Kalium-Mercurijodid nachgewiesen werden. Der nach dem Zersetzen des Bleisalzes mit Schwefelwasserstoff gewonnene Verdampfungsrückstand gab an Aether geringe Mengen einer intensiv nach Vanillin riechenden Substanz ab.

B. Untersuchung des Holzes.

Das schwach gelblich gefärbte Holzpulver wurde

a) mit Alkohol und hierauf

b) " Aether extrahiert.

Das alkoholische Extrakt gab an Aether Chrysatropaskure ab und dem bleibenden, rotbraunen, harzigen Rückstande konnte durch Erwärmen mit verdünnter Schwefelsäure Cholin entzogen werden.

Der atherische Auszug enthielt ebenfalls Chrysatropasäure and ausserdem eine weisse, leicht schmelzbare und auf Papier nicht verschwindende Fettflecke erzeugende Substanz. Dieselbe wurde von konzentrierter Schwefelsäure verbrannt, war löslich in Kalilange und zersetzte sich beim Erhitzen für sich oder mit primărem Kaliumsulfat unter Entwickelung von Acrolein.

Aus diesen Befunden geht hervor, dass bei der Fabiana inbricata das Vorkommen von Cholin und Chrysatropasäure sich nicht auf die Blätter beschränkt, sondern dass die beiden genanten Verbindungen auch in den holrigen Teilen der geuanten Pflanze enthalten sind.

Isolierung und Identifizierung der beiden Verbindungen geschah in der im Vorhergehenden beschriebenen Weise.

\section{Untersuchung der beiden Extrakte.}

C. Das Fluid-Extrakt - der von den Herren Parke, Davis \& Co. erhaltenen, 400,0 g fassenden Originalflasche entnommen - bildete eine dunkel-braun-grüne, alkoholische, stark klebende Flüssigkeit von 0,9026 spez. Gew. bei $15^{\circ}$, von saurer Reaktion und aromatisch-harzig-pfefferartigem Geruch und Geschmack, welche reichlich farblose Prismen des weiterhin beschriebenen Fabianaresens suspendiert enthielt. zähe Masse.

D. Das Extractum spissum bildete eine grün-schwarze,

Nachdem das Fluid-Extrakt durch Destillation und Eindampfen im Wasserbade vom Alkohol befreit war, wurden beide Extrakte zunächst so lange mit Wasser in der Wärme extrahiert. als dieses noch 
sauer reagierte. Diese wässerigen Auszüge zeigten übereinstimmend folgendes Verhalten:

a) Verduinnte Schwefelsäure erzeugt gelbliche, amorphe Niederschläge und nach dem Alkalisieren mit Ammoniak tritt eine schön blaue Fluorescenz auf;

b) mit Galle und konzentrierter Schwefelsäure entsteht die Pettenkofer'sche Glykose-Reaktion;

c) alkalische Kupferlösung wird schon bei gelindem Erwärmen kräftig reduziert.

In den nach dem Eindampfen der wässerigen Lösungen hinterbleibenden Rückstănden konnten ausser Chrysatropasänre. Cholin, Fabianatannoid und - nach dem Erhitzen mit $1 \%$ iger Schwefelsăure - Fabianol keinerlei sonstige charakteristische Terbindungen nachgewiesen werden.

Aus den nach der Behandlung mit Wasser hinterbliebenen, weichen Extraktrückständen konnte das weiterhin beschriebene Fabianaresen und - in der oben beschriebenen Weise durch Destillation im Damptstrome - Fabianol isoliert werden. Der Versuch wurde jedoch insofern modifiziert, als - zur Prïfung des spaltenden Einflusses der Alkalien auf das "Weichharz" und mit Riicksicht auf die voranssichtlich damit verbundene grössere Ausbeute an ätherischem Oel das Extrakt zunächst in Natronlauge gelöst und die Destillation derart in stark alkalischer Lösung ausgefïhrt. wurde. In der That ergah dieser Versuch in mehrfacher Hinsicht interessante Resultate. Abgesehen von der grösseren Oelausbeute erhielt ich aus dem schwarzbraunen, mit Wasser verdünnten und filtrierten Iestillationsrückstande beim Uebersättigen mit. Schwefelsäure einen hellgrauen, etwas harzigen Niederschlag, dessen alkoholische Lösung nach dem Entfärben mit Tierkohle beim freiwilligen Verdunstenlassen über Schwefelsäure tarblose Krystalle lieferte. Das gelbrot gefärbte, saure Filtrat von diesem Niederschlage roch deutlich nach Buttersäure! Dasselbe wurde mit Baryumkarbonat neutralisiert. Das Filtrat vom Baryumsulfat-Niederschlage hinterliess nach dem Eindampfen einen zunächst noch rot gefärbten Salzrückstand, welcher aber, nach dem Entfärben mit Tierkohle, in Form breiter, farbloser Prismen erhalten wurde. Eine nähere Untersuchung dieser beiden Körper musste vor der Hand wegen Mangels an Material unterbleiben. Wie aus der im Vorhergehenden skizzierten Untersuchung hervorgeht, enthält die Fabiana imhricata aber ansser den bereits besprochenen noch zwei weitere charakteristische Verbindungen: ein in das ätherische Extrakt der Blätter übergehendes und auch in den beiden käuflichen Extrakten enthaltenes Harz (Fabianaresen) und eine aus dem wässrigen, bezw. alkoholischen Auszug der 
Blätter erhältliche und wie das Fabianaresen auch in den beiden kăuflichen Extrakten vorkommende, eigentümliche Gerbsäure -- das Fabianatannoid. Handelt es sich lediglich un die Gewinnung dieser beiden Körper, so empfiehlt es sich, die Blätter einfach nacheinander mit Chloroform und mit heissem Wasser zu extrahieren. Ersteres nimmt das Fabianaresen, letzteres das Fabianatannoid auf.

Das ausser dem Fabia nares en noch Fett, Wachs und Chrysatropasäure enthaltende und durch Chlorophyll griin gefärbte Chloroformextrakt wird mit verdünntem kaltem Alkohol gewaschen, hierauf in siedendem Alkohol gelöst und die Lösung mit, Tierkohle entfärbt. Während des Erkaltens scheidet sich aus der filtrierten Lösung das Fabianaresen in völlig weissen Krystallen aus.

Der reine Körper stellt ein schneeweisses, körniges, aus Mikro. prismen bestehendes Pulver dar. Die Substanz ist stickstofffrei. Sie schmilzt gegen $280^{\circ}$ und sublimiert bei vorsichtigem Erhitzen, obme Zersetzung zu erleiden, in Form farbloser, haarfeiner, verfilzter Nadeln. Die Identität derselben mit dem nicht sublimierten Körper ergiebt sich suhon aus der dem letzteren eigentümlichen, schönen Farbenreaktion mit konzentrierter Schwefelsäure. Kalte konzentrierte Schwefelsäure färbt sich und den Körper gelb und bei gelindem, vorsichtigem Erwärmen nehmen beide alsbald eine intensiv ziegelrote Farbe an. Beim Verdünnen dieser roten Lösung mit Wasser scheidet sich ein farbloser, amorpher Niederschlag aus, während Alkohol und Aether lediglich Entfärbung bewirken. Die verdünnte Lösung des Körpers in konzentrierter Schwefelsäure färbt sich in der Kälte nach mebrstündigem Stehen, beim Erwärmen sofort rotgelb mit grüner Fluorescenz, wobei die Farbentöne alle Nuancen von gelb bis rot durchlaufen. Bei stärkerem Erhitzen tritt völlige Zersetzung unter Verkohlung ein. Löst man den Körper zunächst in Chloroform und fügt dann erst konzentrierte Schwefelsäure hinzu, so geht das Reaktionsprodukt mit prächtiger, hochroter Farbe in jenes über. Beim Kochen mit verdünnter Schwefelsäure entwickelt sich ein angenehmer Geruch nach Cuminol (Cuminaldehyd)! Auf Platinblech erhitzt, schmilzt der Körper zunächst zu einer gelben Flüssigkeit, bräunt sich dann und verbrennt schliesslich mit leuchtender Flamme, ohne Rückstand $z u$ hinterlassen und unter Verbreitung eines angenehmen, balsamischen Geruches. Das Fabianaresen ist unlöslich in Wasser, schwer löslich in kaltem, leicht aber in siedendem Alkohol, sowie in Phenol, Chloroform und Aether. Auch von siedendem Eisessig wird es ziemlich leicht grelöst; beim Erkalten der Lösung scheidet sich aber der grösste Teil wieder in Mikrokrystallen aus. Die Lösungen in neutralen Solventien besitzen neutrale Reaktion. Wird die Lösung in Phenol 
anter. Zugabe eines Kondensationsmittels bis zum Siedepunkt des Phenols erhitzt, so nimut dieselbe charakteristische Färbungen an, und zwar färbt sich dieselbe bei Verwendung von Chlorzink gelbbraun, während nach Zugabe eines Tropfens Schwefelsäure und gelindem Erwărmen eine schön rosenrote, alsbald in dunkel-purpurrot übergehende Färbung auftritt.

Nach Lyons (1. c.) soll das „Harz“ ausser in Chloroform und Aether auch in Alkalien leicht löslich sein: eine Angabe, welche ich jedoch nicht bestätigen kann. Die ebenfalls rou Lyons herrührende Angabe, dass die (alkoholische?) Lösung des Harzes beim Alkalisieren eine intensiv blaue Fluorescenz annehme, ist nicht auf Rechnung des Harzes zu setzen, sondern erklärt sich durch die Gegenwart von Spuren der im vorhergehenden beschriebenen Chrysatropasäure in diesem.

Aus dem gesamten, im nachstehenden noch näher zu beleuchtenden Verhalten dieses Körpers geht hervor, dass in demselben ein Vertreter aus der durch die Untersuchung $\lrcorner n$ von Tschirch und dessen Schülern er $*$ chlossenen Klasse der Resene vorliegt und empfiehlt es sich daher, denselben durch die bereits mehrfach gebrauchte Bezeichnung „F abianaresen " zu unterscheiden.

Mit der Frage nach der Elementarzusammensetzung des Fabianaresens beschäftigten sich zuerst Trimble und Schröter (s. o. l. c.). Dieselben isolierten das Fabianaresen - in Fortsetzung der Untersuchungen von Deitz - aus dem in Alkohol löslichen Teil des Aetherextraktes und gelangten aut Grund der als Mittel aus sechs Analysen gewonnenen Werte:

$$
\text { C: } 77,47 \quad \mathrm{H}: \quad 10,93
$$

zur Annahme der Formel:

$$
\left(\mathrm{C}_{18} \mathrm{H}_{31} \mathrm{O}_{2}\right) \mathrm{x} \text {. }
$$

Obgleich nun der beigesetzte Exponent $(x)$ den sonst gegen diese Formel mit Rücksicht auf das Gesetz der paaren Atomzahlen zu erhebenden Einwand der Unzulässigkeit ausschliesst, glaube ich dennoch. dass dem Fabianaresen aus den weiterhin zu erörternden Gründen nicht diese, sondern die Formel $\mathrm{C}_{18} \mathrm{H}_{30} \mathrm{O}_{2}$, bezw. der verdreifachte Ausdruck $\mathrm{C}_{54} \mathrm{H}_{90} \mathrm{O}_{6}$ zukommt:

Gefunden (Trimble u. Schröter): $\quad$ Berechnet für $\mathrm{C}_{18} \mathrm{H}_{30} \mathrm{O}_{2}=278$ :

$$
\begin{array}{ccc}
\text { Proz. C } & 77,47 \\
\# & \text { H } & 10,93
\end{array}
$$

77,69

10,79 .

Für die einfache Formel spricht - abgesehen von den weiterhin noch mitzuteilenden Elementaranalysen des Fabianaresens selbst (s. Acetylderivat und Verhalten zu alkoholischer Kalilauge) - der Bromgehalt des gewonnenen farblosen Bromderivates (s. d.) und die Molekulargewichts-Bestimmung: 
$0,1430 \mathrm{~g}$ des bei $105^{0}$ bis zur Gewichtskonstanz getrockneten Bromderivates lieferten bei der Brombestimmung nach Carius:

$$
0,1235 \mathrm{~g} \mathrm{Ag} \mathrm{Br}=36,71 \% \mathrm{Br} \text {. }
$$

Hieraus ergiebt sich, unter Zugrundelegung der obigen, einfachen Formel, für dasselbe die Zusammensetzung: $\mathrm{C}_{18} \mathrm{H}_{28} \mathrm{Br}_{2} \mathrm{O}_{2}$.

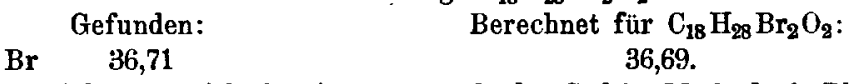

Die Molekulargewichtsbestimmung nach der Gefrier-Methode in Phenol lieferte folgende Werte:

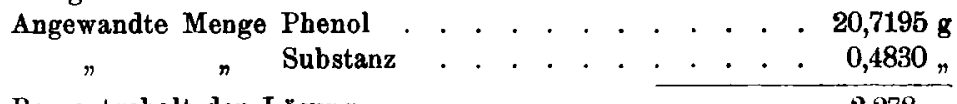

Prozentgehalt der Lösung . . . . . . . . . . . . . $\mathbf{2 , 2 7 8}$

Erstarrungspunkt des Phenols (Mittel aus drei Ablesungen) 3,73 $"$ der Lösung (,$n$ vier,$\quad) \quad 3,12$

Depression . . . . . . . . . . . . . . . . . . 0,61 .

Hieraus ergiebt sich für das Molekulargewicht:

$$
\begin{aligned}
& \mathrm{M}=\mathrm{c} \cdot \frac{\mathrm{p}}{\mathrm{t}}=76 \cdot \frac{2,278}{0,61}=283,8 . \\
& \text { Gefunden: } \quad \text { Berechnet für } \mathrm{C}_{\mathbf{1 8}} \mathrm{H}_{\mathbf{3 0}} \mathrm{O}_{\mathbf{2}} \text { : } \\
& 283,8278 .
\end{aligned}
$$

Trotz alledem glaube ich jedoch, dass dem Fabianaresen nicht diese einfache, sondern die verdreifachte Formel $\mathrm{C}_{54} \mathrm{H}_{90} \mathrm{O}_{6}$ zukommt und zwar aus zweierlei Gründen, einmal wegen des auffallend hohen Schmelzpunktes dieser Substanz und anderenteils, weil alsdann das Fabianaresen in eine einfache Beziehung zu dem oben beschriebenen $\mathrm{Fabianol} \mathrm{C}_{54} \mathrm{H}_{80} \mathrm{O}_{4}$ tritt:

$$
\underbrace{\mathrm{C}_{54} \mathrm{H}_{90} \mathrm{O}_{4}}_{\text {Fabianol }}+\mathrm{O}_{2}=\underbrace{\mathrm{C}_{54} \mathrm{H}_{90} \mathrm{O}_{6}}_{\text {Fabianaresen }}
$$

d. h. das Fabianaresen würde als ein durch Aufnahme zweier weiterer Sanerstcffatome entstandenes Oxydationsprodukt des Fabianols erscheinen.

Bromderivate des Fabianaresens. Die Einwirkung von Brom auf das Fabianaresen ist eine verschiedenartige, je nachdem man in alkoholischer, bezw. ätherischer, oder aber in eisessigsaurer Lösung arbeitet. Im ersteren Falle resultiert ein farbloses, im letzteren ein gelb gefarbtes Produkt.

Das farblose Bromderivat entsteht beim Versetzen der ätherischen, bezw. alkoholischen Lösung des Fabianaresens mit Brom. Arbeitet man in alkoholischer Lösung, so ist es vorteilhaft, die Lösung zum Zweck völliger Bromierung längere Zeit auf dem Wasserbade zu erwärmen. Das Bromderivat krystallisiert alsdann beim langsamen Erkalten der Lösung in farblosen, büschelförmig vereinigten Prismen aus. 
Von Eisessig wird dasselbe beim Erwärmen reichlich aufgenommen. Nach dem Erkalten scheidet sich der grösste Teil der Verbindung amorph ab, während aus der abfiltrierten Mutterlauge der gelöst gebliebene Rest durch langsames Verdunstenlassen des Lösungsmittels in Form farbloser Prismen erhalten werden kann. Als zur Entfernung des im Ueberschuss vorhandenen Broms die alkoholische Lösung des Bromderivates in kaltes, ammoniakalisches Wasser eingetragen wurde, blieb das Bromprodukt in dem derart entstandenen, verdünnten a mmoniakalischen Alkohol gelöst. Durch Ansäuern der Flüssigkeit mit Essigsäure liess sich dasselbe aber sofort in Form eines blendend weissen Niederschlages zur Ausfällung bringen.

Der für die Sicherstellung stattgehabter Bromierung notwendige Nachweis des Halogens in dem gewonnenen Produkte liess sich nicht nach der ebenso einfachen, als eleganten Methode von Beilstein ${ }^{1}$ ) - durch Verglühen mit Kupferoxyd am Platindrahte - ausführen, da Vorversuche lehrten, dass das Fabianaresen das Verhalten einiger anderer organischer Substanzen, z. B. der Benzoesäure und benzoesauren Salze teilt, indem dasselbe beim Erhitzen mit Kupferoxyd am Platindraht an sich schon Grünfärbung der Flamme verursacht. Es wäre nicht uninteressant, wenn auch die übrigen, durch die Arbeiten ron Tschirch und dessen Schülern bekannt gewordenen Resene nach dieser Richtung einer vergleichenden Prüfung unterzogen würden. Der Bromnachweis wurde daher in der üblichen Weise durch Zusammenschmelzen der Verbindung mit Kaliumhydroxyd, Aufnehmen der Schmelze mit verdünnter Schwefelsäure und Versetzen der Lösung mit Chlorwasser und Schwefelkohlenstoff geführt.

Das farblose Bromderivat - dessen Bromgehalt, wie bereits mitgeteilt, der Formel $\mathrm{C}_{18} \mathrm{H}_{28} \mathrm{Br}_{2} \mathrm{O}_{2}$ entspricht - ist durch eine besonders charakteristische und schöne chromatische Reaktionsfolge ausgezeichnet. Bei vorsichtigem Erwärmen mit konzentrierter Schwefelsäure in einer Porzellanschale löst sich die Substanz zunächst - wie das Fabianaresen - mit ziegelroter Farbe, die jedoch nach und nach durch Purpurrot in Rotviolett übergeht. Versetzt man in diesem Stadium der Färbung die Flüssigkeit vorsichtig tropfenweise mit Wasser, so nimmt dieselbe eine blauviolette Färbung an, welche nach Zugabe einer grösseren Menge Wasser dann weiter in ein prächtiges Grasgrün übergeht, und nach einigem Stehen scheidet sich aus der Flüssigkeit ein ebenso gefärbter Niederschlag aus. Setzt man hingegen das Erwärmen der Lösung in konzentrierter Schwefelsäure über den oben erwähnten Punkt fort, so geht die violett-rote Färbung in Sepiabraun,

1) Ber. d. Deutsch. chem. Ges. 5 (1872), p. 620. 
bezw. - nach Zugabe von wenig Wasser - in ein schmutziges Blauviolett über, und beim Verdünnen mit mehr Wasser tritt eine dunkelgrüne Färbung ein.

Wird die eisessigsaure Lösung des Körpers mit Chromsäure versetzt, hierauf mit Wasser verdünnt und durch Ammoniak das Chromoxydbydrat ausgefällt, so erhält man ein Filtrat, welches nach dem Ansäuern mit Salzsäure einen weissen, amorphen Niederschlag giebt.

Das gefärbte Bromderivat wurde durch mehrstündiges Kochen der eisessigsauren Lösung des Fabianaresens mit Brom am Rückfluss. kühler gewonnen. Die gelb gefürbte Flüssigkeit wurde in Wasser eingegossen, der gelbe zum Teil amorph, zum Teil krystallisiert ausfallende Niederschlag in Alkohol gelöst und aus dieser Lösung die Verbindung durch Eingiessen in Wasser wiederum ausgefällt. Dieselbe stellt nach dem Trocknen ein hellgelbbraunes Pulver dar. Das erste wässerige essigsaure Filtrat vom Bromniederschlage war durch eine schön maigl üne Fluorescenz ausgezeichnet. Der die Fluorescenz bewirkende Körper ist sehr leicht löslich in Chloroform und konnte daher der wässerigen Flüssigkeit durch einmaliges Ausschütteln mit diesem letzteren entzogen werden. Beim Verdunsten dieser Chloroformlösung machte sich unverkennbar der bereits früher - bei Verarbeitung des Extr. spissum - beobachtete Geruch nach Buttersäure bemerkbar. Im weiteren Verlauf der Untersuchung zeigte es sich, dass diese Fluorescenz des wässerig-essigsauren Filtrates durch noch gelöst gebliebene Spuren der Bromverbindung verursacht worden war, indem das Bromderivat selbst von Chloroform sehr leicht zu einer rotbraunen, prachtvoll russisch-grün fluorescierenden Flüssigkeit gelöst wird. Auch in Benzol und Schwefelkohlenstoff ist das gelbe Bromprodukt löslich.

Die mit Chloroform ausgeschüttelte, wăsserig-essigsaure Flüssigkeit war noch gelb gefärbt und hinterliess einen ebensolchen Verdunstungsrückstand. Die wässerige Lösung desselben gab mit Ferrichlorid und Chlorbaryum rötlich-braune Fällungen.

Wird die alkoholische, ebenfalls grün fluorescierende Lösung des gelben Bromderivates mit metallischem Natrium, bezw. mit Natriumamalgam behandelt, so verschwindet die Fluorescenz und es entsteht eine braun gefärbte Flüssigkeit. Dieselbe wurde mit Kohlensäure behandelt, um das Natrium zu entfernen, filtriert, Filtrat eingedampft, Rückstand in Wasser gelöst und die wässerige Lösung mit Chloroform extrahiert. Die wässerige Flüssigkeit hinterliess auch diesmal eine geringe Menge eines gelben, in Wasser löslichen Körpers, welche: durch Ferrichlorid gefällt wurde. 
Konzentrierte Schwefelsäure löst das gelbe Bromderivat beim Erwärmen zu einer sepiabraunen Flüssigkeit, welche auf Zusatz von Wasser eine schmutzig-blau-violette Farbe annimmt. Beim Verdünnen mit Wasser entsteht ein sepiabrauner Niederschlag.

Beim Erhitzen auf seinen Schmelzpunkt erleidet das gelbe Bromderivat - wie aus dem nachstehenden Verhalten hervorgeht - Zersetzung, unter Entwickelung sauer reagierender Produkte: Fine Probe des über Schwefelsäure bis zum konstanten Gewicht getrockneten Körpers wurde in einem Probierglase, welches nebst einem Thermometer in ein mit konzentrierter Schwefelsäure gefülltes Becherglas tauchte, langsam bis zum beginnenden Schmelzen erhitzt. In dem oberen Teile des Probierglases befand sich frei aufgehängt ein schmaler Streifen angefeuchtetes blaues Lackmuspapier, welches durch einen Wattebausch und mehrfache, über die Oeffnung des Probierglases gestülpte und mit Natronlauge getränkte Lagen Filtrierpapier gegen von aussen kommende Săuredämpfe geschützt war. Gegen $50^{\circ}$ begann die Substanz sich dunkeler zu färben und schmolz bei $96^{\circ}$. Bereits bei $80^{\circ}$ trat aber an den Rändern des Lackmuspapierstreifens schon eine leichte Rötung auf, welche sich im Augenblick des Schmelzens der Substanz über die ganze Fläche verbreitete. Ein in diesem Augenblick in das Probierglas eingeführter, mit Ammoniak benetzter Glasstab umgab sich mit einem deutlich sichtbaren Nebel.

Hiernach dürfte aber das gelbe Bromderivat als ein Bromid und zwar - mit Rücksicht auf seine charakteristische Färbung - voraussichtlich als ein Perbromid des Fabianaresens mit einem nur locker gebundenen (Essig - oder Bromwasserstoff - [?]) Săurerest betrachtet werden. Aber nicht nur dieser letztere, sondern auch der die Farbung bedingende Bromanteil ist leicht aus der Verbindung zu entfernen. Wird die konzentrierte Lösung des gelben Bromderivates in Benzol nach und nach mit $50 \%$ igem Alkohol versetzt, so fällt bei genügender Verdünnung ein weisses Bromderivat als völlig farbloser Niederschlag aus. In derselben Weise liess sich aus der konzentrierten Lösung in Chloroform durch Fällen mit Alkohol ein farbloses Produkt gewinnen. Aus dem Filtrat konnte durch Einstellen in Schnee eine weitere und zwar aus farblosen Prismen bestehende Ausscheidung gewonnen werden.

Damit wird es auch verständlich, dass weder durch die Elementar. analyse, noch durch die Bestimmung des Bromgehaltes sichere Aufschlüsse über die wahre Zusammensetzung dieses gefärbten Bromderivates zu erlangen waren.

I. $0,3568 \mathrm{~g}$ der über Schwefelsäure bis zur Gewichtskonstanz getrockneten Substanz lieferten bei der Verbrennung mit Kupferoxyd und vorgelegter Silberspirale im Sauerstoffstrome: 


$$
\begin{aligned}
& 0,6241 \mathrm{~g} \mathrm{CO}=47,70 \% \mathrm{C} \text { und } \\
& 0,1840 \mathrm{H}_{2} \mathrm{O}=5,72, \mathrm{H} .
\end{aligned}
$$

II. $0,2775 \mathrm{~g}$ der ebenfalls über Schwefelsäure getrockneten Substanz lieferten, nach Carius bestimmt:

$$
0,2160 \mathrm{~g} \mathrm{AgBr}=33,11 \% \mathrm{Br} \text {. }
$$

III. $0,3210 \mathrm{~g}$ der bei $90^{\circ}$ - also nahe am Schmelzpunkt bis zum konstanten Gewicht getrockneten Substanz lieferten:

$$
0,2810 \mathrm{~g} \mathrm{Ag} \mathrm{Br}=37,25 \% \mathrm{Br} \text {. }
$$

Es erscheint nicht ausgeschlossen, dass unter den zu diesen gefärbten Bromderivaten führenden Versuchsbedingungen gleichzeitig verschieden hoch bromierte Körper entstehen, welche aber den Bromüberschuss sämtlich mehr oder weniger leicht wieder abgeben. Hierfür spricht der Umstand, dass bej einer anderen Darstellung ein Produkt erhalten wurde, welches bei $68^{\circ} \mathrm{zu}$ sintern begann und bei $78^{\circ}$ partiell zu einer hell-goldgelben, öligen Flüssigkeit schmolz, während eine rotbraune, körnige Masse zurückblieb. Aus den heiss gesättigten Lösungen in Eisessig und in Alkohol scheidet sich beim Erkalten ein Teil der Verbindung in fast farblosen Blättchen aus. Hiernach wïrde auch der Versuch, aus dem oben mitgoteilten Zahlenmaterial eine Formel abzuleiten, zunächst noch verfrüht erscheinen.

Der Versuch, die Bromierung des Fabianaresens in Chloroformlösung auszuführen, ergab nach den bisherigen Erfahrungen - trotz der zu Anfang glatt vor sich gehenden Entfärbung und trotzdem die bis zur Rotfärbung mit Brom versetzte Flüssigkeit noch einige Zeit zum Sieden erhitzt wurde - kein günstiges Resultat.

\section{Acylderivate des Fabianaresens.}

Von solchen wurde die Darstellung des Acetyl- und BenzoylDerivates versucht.

Zur Gewinnung eines Acetylderivates wurde das Fabianaresen zunächst mehrere Stunden mit Eisessig am Rückflusskühler zum Sieden erhitzt. Obwohl nun die eisessigsaure Lösung beim Eintragen in kaltes Wasser sofort zu einem Brei farbloser, glänzender Nadeln erstarrte, so bestand das Reaktionsprodukt doch lediglich nur aus unverändertem Fabianaresen. Beim Erhitzen mit Alkohol und Schwefelsăure lieferte dasselbe kein en Essigäther, andererseits stimmte es sowohl in seinem Verhalten gegen konzentrierte Schwefelsäure - orang egel be, beim Erwärmen in ziegelrot übergehende Färbung -, wie auch hinsichtlich seiner prozentualen Zusammensetzung mit jenem überein. $0,2208 \mathrm{~g}$ der bei $100^{\circ}$ bis zum konstanten Gewicht getrockneten Substanz lieferten bei der Verbrennung mit Kupferoxyd im Sauerstoffstrome:

$$
\begin{aligned}
& 0,6235 \mathrm{~g} \mathrm{CO}=77,01 \% \mathrm{C} \text { und } \\
& 0,2099, \mathrm{H}_{2} \mathrm{O}=10,56, \mathrm{H} .
\end{aligned}
$$




\begin{tabular}{|c|c|c|}
\hline \multicolumn{2}{|c|}{ Geỉunuen: } & \multirow{3}{*}{$\begin{array}{c}\text { Berechnet für } \mathrm{C}_{54} \mathrm{H}_{80} \mathrm{O}_{6}=834: \\
77,69 \\
10,79\end{array}$} \\
\hline P'roz. C & 77,01 & \\
\hline $\mathrm{H}$ & 10,56 & \\
\hline
\end{tabular}

Hierans folgt sonach, dass eine eventuelle Acetylierung auf diesem Wege nicht zu erreichen ist, und ferner, dass das Fabianaresen, ohne Veränderung zu erleiden, aus Eisessig umkrystallisiert werden kann. Anders gestalteten sich dagegen die Verhältnisse, als 2,0 g Fabianaresen mit 2,0 g wasserfreiem Natriumacetat und $10,0 \mathrm{~g}$ Essigsäureanhydrid während drei Stunden im Druckrohr auf $120^{\circ}$ erhitzt wurden. Das Reaktionsprodukt wurde in Wasser eingegossen, durch Behandeln mit Eisessig von noch unverändertem Fabianaresen befreit und hierauf auf dem Filter mit Wasser ausgesüsst. Es ist unlöslich in Wasser und Eisessig, leicht löslich dagegen in heissem absolutem Alkohol. Aus der letyteren Lösung wird es, nach dem Entfärben mit Tierkohle, in farblosen, prächtig glasglänzenden Prismen erhalten. Gegen $215^{\circ}$ färbt sich die Substanz gelb, wird teigig, sintert zusammen und schmilzt endlich - nach zwei übereinstimmenden Beobachtungen - bei $234^{0} \mathrm{zu}$ einer gelben Flüssigkeit.

$0,0838 \mathrm{~g}$ der bei $100^{\circ}$ bis zur Gewichtskonstanz getrockneten Substanz lieferten bei der Verbrennung mit Kupferoxyd im Sauerstoffstrome:

$$
\begin{aligned}
& 0,2310 \mathrm{~g} \mathrm{CO}_{2}=75,18 \% \mathrm{C} \text { und } \\
& 0,0727, \mathrm{H}_{2} \mathrm{O}=9,66, \mathrm{H} .
\end{aligned}
$$

Gefunden :

Berechnet für :

$$
\begin{array}{ccr}
\text { Proz. C } & 75,18 \\
n & \text { H } & 9,66
\end{array}
$$$$
\underbrace{\left(\mathrm{C}_{18} \mathrm{H}_{29}\left(\mathrm{CH}_{8} \mathrm{CO}\right) \mathrm{O}_{2}\right.}_{320} \text { bezw. } \underbrace{\mathrm{C}_{54} \mathrm{H}_{87}\left(\mathrm{CH}_{8} \mathrm{CO}\right)_{8} \mathrm{O}_{6}}_{960}
$$

Diese Zahlen lassen aber erkennen, dass das gewonnene Produkt in der 'That die Zusammensetzung eines Mono- bezw. 'TriacetylFabianaresens besass.

Die durch Eingiessen des Reaktionsproduktes in Wasser gewonnene wässerige Flüssigkeit besass einen charakteristischen, ätherischen Geruch. Durch Destillation im Luftstrome lieferte dieselbe ein Destillat, aus dem sich auf Zugabe von Kaliumhydroxyd und Jod-Jodkalium reichliche Mengen von Jodoform abschieden, welch' letzteres sowohl durch die charakteristische Form - hexagonale Täfelchen - der aus Alkohol gewonnenen Krystalle, wie auch durch den bei $119^{\circ}$ liegenden Schmelz. punkt identifiziert werden konnte.

Durch Sättigen des Destillats nit Kaliumkarbonat schied sich weiterhin daraus ein gelbes, intensiv nach Pfefferminze, bezw. nach Paraldehyd riechendes und in Aether lösliches Oel ab. Dasselbe reduziert ammoniakalische Silbernitratlösung, ist aber gegen Fuchsinschwefligsäure indifferent. 
Das Auftreten dieser Spaltungsprodukte deutet demnach auf einen nebenher gehenden, tieferen Molekularzerfall des Fabianaresens hin. Die im Anschluss an diese Versuche unternommene Prüfung des Fabianaresens auf vorhandene Methoxylgruppen ergab ein negatives Resultat.

Auch unter diesen, die Acetylierung des Fabianaresens ermöglichenden, Versuchsbedingungen ist aber die Reaktion immer noch eine nur teilweise. Der dem Reaktionsprodukt durch Behandeln mit Eisessig entziehbare, nicht unbedeutende Anteil desselben war, wie aus den nachstehenden Zahlen ersichtlich, unverändertes Fabianaresen.

$0,3838 \mathrm{~g}$ der bei $100^{\circ}$ bis zum konstanten Gewicht getrockneten Substanz lieferten bei der Verbrennung mit Kupferoxyd im Saucrstoffstrome:

$$
\begin{aligned}
& 1,0882 \mathrm{~g} \mathrm{CO}_{2}=77,32 \% \mathrm{C} \text { und } \\
& 0,3670, \mathrm{H}_{2} \mathrm{O}=10,62, \mathrm{H} .
\end{aligned}
$$

\begin{tabular}{|c|c|c|}
\hline \multicolumn{2}{|c|}{ Gefunden: } & \multirow{3}{*}{$\begin{array}{c}\text { Berechnet für } \mathrm{C}_{18} \mathrm{H}_{30} \mathrm{O}_{\mathbf{2}} \text { bezw. } \mathrm{C}_{\mathbf{5 4}} \mathrm{H}_{90} \mathrm{O}_{6} \text { : } \\
77,69 \\
10,79 .\end{array}$} \\
\hline Proz. C & 77,32 & \\
\hline $\mathrm{H}$ & 10,62 & \\
\hline
\end{tabular}

Zur Gewinnung eines Benzoylderivates wurden je $2,0 \mathrm{~g}$ Fabianaresen und Benzoesäureanhydrid während $7 \frac{1}{2}$ Stunden im Oelbade auf $150-160^{\circ}$ erhitzt. Die beim Erwärmen der Mischung zunächst resultierende klare, gelblich gefürbte Flüssigkeit beginnt nach vierstündigem Erhitzen sich $\mathrm{zu}$ verdicken, um endlich krystallinisch zu erstarren. Das gebildete Benzoyl-Fabianaresen ist unlöslich in Alkohol und Aether und lässt sich daher durch Behandeln mit heissem Alkohol leicht von noch unverändertem Resen, bezw. Benzoesäureanhydrid befreien. Von Chloroform wird die Verbindung schon in der Kälte und zwar leicht und reichlich gelöst. Versetzt man die konzentrierte Chloroformlösung mit Alkohol, so tritt nach kurzer Zeit Trübung ein und der Körper făllt in prächtig ausgebildeten Nadelaggregaten aus. Beim Erwärmen unter Alkohol schmilzt die Verbindung zu öligen Tropfen zusammen, welche beim Erkalten zu kugeligen Krystallwarzen erstarren. Dieselben besitzen den Schmelzpunkt $61^{\circ}$. Vorsichtig erhitzt, sublimiert die Verbindung zum Teil, während die geschmolzene Masse beim Erkalten zu einem Haufwerk wohlausgebildeter, farbloser, sehr steiler rhombischer Prismen erstarrt.

Ausser durch den auffallend niedrigen Schmelzpunkt unterscheidet sich die gewonnene Verbindung besonders noch durch ihr Verhalten zu konzentrierter Schwefelsäure von dem Fabianaresen. Während dieses letztere, wie mehrfach erwähnt wurde, beim Erwärmen mit konzentrierter Schwefelsäure eine höchst charakteristische ziegelrote Lösung liefert, aus welcher Wasser die Verbindung in Form eines farblosen Niederschlages wieder ausfällt, geht das Benzoyl-Fabiana- 
resen mit schön orangegelber Farbe in Lösung, welche durch Wasser nur opalisierend getrübt, nicht aber gefällt wird.

Die Elementaranalyse der über Schwefelsäure bis zur Gewichtskonstanz getrockneten Substanz ergab folgende Werte:

$0,2724 \mathrm{~g}$ mit Kupferoxyd im Sauerstoffstrome verbrannt, lieferten:

$$
\begin{aligned}
& 0,2247 \mathrm{~g} \mathrm{H}_{2} \mathrm{O}=9,16 \% \mathrm{H} \text { und } \\
& 0,7737, \mathrm{CO}_{2}=77,46 \% \mathrm{C} .
\end{aligned}
$$

Diese letztere Zahl kann jedoch nur als ein Mindestwert in Betracht gezogen werden, da infolge eines Unfalls die letzten Anteile Kohlensäure verloren gingen. Dagegen besitzen die H-Prozentzahlen ihre volle Giltigkeit. Dieselben führen aber zu dem einfachsten Formelwerte:$$
\mathrm{C}_{25} \mathrm{H}_{84} \mathrm{O}_{8} \text { d. h. } \mathrm{C}_{18} \mathrm{H}_{29}\left(\mathrm{C}_{6} \mathrm{H}_{5} \mathrm{CO}\right) \mathrm{O}_{2} \text {. }
$$

Gefunden:

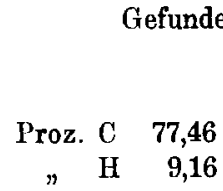

Berechnet für:

$$
\underbrace{\mathrm{C}_{18} \mathrm{H}_{29}\left(\mathrm{C}_{6} \mathrm{H}_{5} \mathrm{CO}\right) \mathrm{O}_{2}}_{382} \text { bezw. } \underbrace{\mathrm{C}_{34} \mathrm{H}_{87}\left(\mathrm{C}_{6} \mathrm{H}_{5} \mathrm{CO}\right)_{8} \mathrm{O}_{6}}_{1146}
$$

78,53

8,90

d. h. die Verbindung darf mit einem hohen Grade von Wahrscheinlichkeit als ein Monobenzoyl-Fabianaresen: $\mathrm{C}_{18} \mathrm{H}_{29}\left(\mathrm{C}_{6} \mathrm{H}_{5} \mathrm{CO}\right) \mathrm{O}_{2}$, bezw. Tribenzoyl-Fabianaresen: $\mathrm{C}_{54} \mathrm{H}_{87}\left(\mathrm{C}_{6} \mathrm{H}_{5} \mathrm{CO}\right)_{8} \mathrm{O}_{6}$ aufgefasst werden.

Die Beibringung weiterer Belege für diese Formel muss ich mir leider - wegen momentanen Mangels an Ausgangsmaterial - vorbehalten.

\section{Verhalten des Fabianaresens gegen Reduktionsmittel.}

1. Einwirkung von metallischem Natrium. - Versetzt man die Lösung von 1,0 g Fabianaresen in $30 \mathrm{ccm}$ Chloroform, welches vorhel durch Behandeln mit Natrium von den letzten Spuren Alkohol befreit und hierauf durch ein getrocknetes Filter filtriert wurde, mit reinem metallischen Natrium, so beginnt alsbald Wasserstoffentwickelung, indem sich um die Natriumstücke gelbe Krusten bilden, die nach und nach abblättern und zu Boden fallen. Nach dem Verreiben und Auswaschen derselben mit Wasser bis zum Verschwinden der alkalischen Reaktion hinterbleibt ein weisses Pulver, welches in Wasser, Alkohol and Chloroform unlöslich ist und beim Verglühen auf Platinblech einen alkalisch reagierenden Rückstand hinterlässt.

$0,0900 \mathrm{~g}$ der bei $100^{\circ}$ bis zum konstanten Gewicht getrockneten Substanz lieferten beim Abrauchen mit Schwefelsäure:

$$
0,0055 \mathrm{~g} \mathrm{Na}_{2} \mathrm{SO}_{4}=1,89 \% \mathrm{Na} \text {. }
$$

Von verdünnter Schwefelsäure wird die Substanz nicht verändert, während mit konzentrierter Säure schon in der Kälte Zersetzung und zwar unter Entwickelung von Schwefligsäureanhydrid eintritt. Beim Erwärmen der Lösung in konzentrierter Schwefelsäure 
tritt die für das Fabianaresen charakteristische, intensiv ziegelrote Färbung auf. Dieses Verhalten - in Verbindung mit dem beobachteten minimalen Natriumgehalte - dürfte wohl die Entstehung einer Natriumverbindung, d. h. eines Natriumsalzes ausgeschlossen erscheinen lassen; vielmehr dürfte es sich um ein Reduktionsprodukt mit - infolge Lösung einer doppelten Bindung - additionell gebundenem Natrium, nach Art der von mir vor kurzem an dieser Stelle beschriebenen Dinatrium- Hydrozimtsäure, ${ }^{1}$ ) handeln, dessen Bildung aber nicht über das Anfangsstadium der Reaktion hinausgekommen ist und welches schon in Berührung mit konzentrierter Schwefelsäure - unter gleichzeitiger Reduktion dieser zu Schwefeldioxyd - wieder oxydiert wird.

2. Einwirkung von Jodwasserstoftsäure und rotem Phosphor. - 1,5 g Fabianaresen, 0,5 g roter Phosphor und 8,0 g Jodwasserstoffsäure vom spez. Gew. 1,7 wurden während drei Stunden in Druckrohr auf $250^{\circ}$ erhitzt. Das Reaktionsprodukt bestand aus einem braun gefärbten, amorphen Kuchen. Aus der heiss bereiteten alkoholischen Lösung desselben schied sich schon beim Erkalten eine geringe Menge einer wachsartigen Substanz aus, und beim Verdünnen der alkoholischen Lösung mit Wasser wurde das Reaktionsprodukt in Form eines weissen Niederschlags erhalten. Derselbe wurde nach dem Auswaschen' mit Wasser und Trocknen nochmals in heissem Alkohol gelöst, die Lösung mit Tierkohle entfärbt und mit Wasser verdünnt bei seite gestellt. Das Reaktionsprodukt wurde auch diesmal wieder nur als weisser, amorpher Niederschlag erhalten, aus dessen ätherischer Lösung der Körper schliesslich in Form eine" weissen, wachsweichen und neutral reagierenden Masse gewonnen wurde.

I. $0,2799 \mathrm{~g}$ der bei $100^{\circ}$ bis zum konstanten Gewicht getrockneten Substanz lieferten bei der Verbrennung mit Kupferoxyd im Sauerstoffstrome: $0,8538 \mathrm{~g} \mathrm{CO}_{2}=83,19 \underset{i 0}{o} \mathrm{C}$ und $0,3197, \mathrm{H}_{2} \mathrm{O}=12,69, \mathrm{H}$.

II. $0,3501 \mathrm{~g}$ lieferten:

$$
\begin{aligned}
& 1,0672 \mathrm{~g} \mathrm{CO}_{2}=83,13_{\%}^{o} \mathrm{C} \text { und } \\
& 0,4005, \mathrm{H}_{2} \mathrm{O}=12,71, \mathrm{H} .
\end{aligned}
$$

Diese Prozentwerte führen aber zu der Formel $\mathrm{C}_{54} \mathrm{H}_{28} \mathrm{O}_{2}$.

I. Gefunden:

Berechnet für $\mathrm{C}_{54} \mathrm{H}_{88} \mathrm{O}_{8}=778$ :

$\begin{array}{cccccc} & & \text { I. } & \text { II. } & \text { Mittel: } & \\ \text { Proz. } & \text { C } & 83,19 & 83,13 & 83,16 & 83,29 \\ \text { ٪ } & \text { H } & 12,69 & 12,71 & 12,70 & 12,59 .\end{array}$

Die Entstehung dieses Reduktionsproduktes aus dem Fabianaresen lässt sich nun aber lediglich unter Zugrundelegung der für dieses

1) Arch. d. Pharm. 236 (1898), pag. 552. 
bereits oben - aus der Zusammensetzung des Fabianols - abgeleiteten Formel $\mathrm{C}_{54} \mathrm{H}_{90} \mathrm{O}_{6}$ erklären und erhält damit diese letztere ihre direkte experimentelle Bestätigung.

Das gewonnene Reduktionsprodukt erscheint alsdann als ein aus dem Fabianaresen durch Ersat\% von vier Sauerstoffatomen durch acht Wasserstoffatome hervorgegangenes

\section{Desoxy-Hydro-Fabianaresen.}

Die Beziehungen der genannten drei Köjper ergeben sich aus der folgenden Zusammenstellung:

$$
\underset{\text { Fauianol (Desoxyfabianaresen) }}{\mathrm{C}_{51} \mathrm{H}_{90} \mathrm{O}_{4} \stackrel{+\mathrm{O}_{2}}{\longrightarrow}} \underset{\text { Fabianaresen }}{\mathrm{C}_{54} \mathrm{H}_{90} \mathrm{O}_{6} \stackrel{-40+8 \mathrm{H}}{\longrightarrow}} \mathrm{C}_{54} \mathrm{H}_{93} \mathrm{O}_{3}
$$

Ausserdem låsst aber der Verlauf der Reaktion auch jetzt schon die Möglichkeit einer vollständigen Reduktion des Fabianaresens roraussehen. Der resultierende Kohlen wasserstoff wïrde die Zusammensetzung $\mathrm{C}_{54} \mathrm{H}_{102}$ besitzen, d. h. der allgemeinen Formel $\mathrm{C}_{n} \mathrm{H}_{2 \mathrm{n}}-6$ der Benzolkohlenwasserstoffe entsprechen!

3. Die Destillation mit Zinkstaub lieferte neben flücitigen Kohlenwasserstoffen geringe Mengen eines gelblichen, empyreumatisch riechenden Oeles.

\section{Verhalten des Fabianaresens gegen Oxydationsmittel.}

Gewühnliche farblose Salpetersäure wirkt nur wenig auf den Körper ein, indem sich beim Erwärmen nur Spuren unter geringer Gelbfärbung der Säure lösen.

Beim Abrauchen mit konzentrierter Salpetersäure bleibt ein gelber Rückstand, welcher sich heim Befeuchten mit Ammoniak rot färbt. Rauchende Salpetersäure löst das Fabianaresen unter Entwickelung von Untersalpetersäure und beim Erkalten scheiden sich aus der Lösung weisse, amorphe Massen aus.

Wird die Lösung des Fabianaresens in konzentrierter Schwefelsiaure mit Liebermann'schem Reagens versetzt und diese Lösung hierauf in Wasser gegossen, so fältt ein weisser, in Aether und Ammoniak leicht löslicher und aus letzterer Lösung durch Säuren wieder fällbarer Körper aus.

Verhalten des Fabianaresens gegen alkoholische Kalilauge. - In der Absicht, eine eventuelle Spaltung des Fabianaresens zu erreichen, wurde die Substanz zunichst mit alkoholischer Kalilauge längere Zeit zum Sieden erhitzt. Nach einiger Zeit entstand ein weisser, sandiger Niederschlag, welcher auf dem Filter mit Wasser ausgesüsst und - zur Entfernung der letzten Reste Alkali - mit verdünnter Schwefelsäure ausgekocht wurde. Derselbe war in Aether 
leicht und reichlich löslich und gab sich - nach dem Verdunsten der ätherischen Lösung - durch seinen bei $280^{\circ}$ liegenden Schmelzpunkt, wie auch durch die Elementaranalyse als unverändertes Fabianaresen zu erkennen.

I. 0,1695 g mit Kupferoxyd im Sauerstoffstrome verbrannt, lieferten: $0,4790 \mathrm{~g} \mathrm{CO}=77,06 \% \mathrm{C}$ und $0,1618, \mathrm{H}_{2} \mathrm{O}=10,60, \mathrm{H}$.

II. $0,2433 \mathrm{~g}$ lieferten:

$$
\begin{aligned}
& 0,6885 \mathrm{~g} \mathrm{CO}_{2}=77,17 \% \mathrm{C} \text { und } \\
& 0,2311, \mathrm{H}_{2} \mathrm{O}=10,55, \mathrm{H} .
\end{aligned}
$$

\begin{tabular}{cccccc}
\multicolumn{5}{c}{ Gefunden: } & Berechnet für \\
& & L. & II. & Mittel & $\mathrm{C}_{54} \mathrm{H}_{90} \mathrm{O}_{6}$ : \\
Proz. C & 77,06 & 77,17 & 77,11 & 77,69 \\
$"$ & H & 10,60 & 10,55 & 10,57 & $10,79$.
\end{tabular}

Verhalten des Fabianaresens gegen schmelzende A lkalien. - 2,0 g Fabianaresen wurden mit 20,0 g Kaliumhydroxyd und 5,0 g Natriumhydroxyd zusammengeschmolzen. Nach ca. einstündigem Schmelzen trat plötzlich unter Schäumęn und unter Entwickelung stark balsamisch riechender Dämpfe Reaktion ein und zugleich schied sich eine schwarze Masse aus. Das gesamte Reahtionsprodukt löste sich leicht in Wasser zu einer gelbbraun gefärbten, olivgrün fluorescierenden Flüssigkeit und konnte daraus durch Uebersättigen mit Salzsäure - wobei eine reichliche Entwickelung von Kohlensäure auftrat - als zunächst noch grau gefärbter, amorpher Niederschlag wieder ausgefällt werden. Das - in Alkohol lösliche Reaktionsprodukt besass sonach den Charakter einer Säure. In dem wässerigen Filtrat vom Salzsäureniederschlag konnten - durch Destillation im Luftstrome - keine flüchtigen Fettsäuren nachgewiesen werden. Der Niederschlag wurde auf dem Filter mit Wasser ausgesüsst, in Alkohol gelöst, die alkoholische Lösurig mit Tierkohle entfärbt und eingeengt. Der hinterbleibende Verdunstungsrückstand schmolz schon auf dem Wasserbade zu öligen Tropfen zusammen. Unlöslich in Ammoniak, löst sich die Säure hingegen leicht in wenig Kalilauge, während auf Zusatz von mehr Kalilauge ein weisser, krystallinischer Niederschlag ausfällt. Alkoholische Bleiacetatlösung erzeugt in der alkoholischen Lösung der Säure keinen Niederschlag. Die freie, trockene, im reinen Zustand farblose Siaure beginnt gegen $125^{\circ} \mathrm{zu}$ sintern, indem sie sich gleichzeitig bernsteingelb, später dunkelgelb färbt. Bei $178-180^{\circ}$ tliesst sie zu einer braunroten Flüssigkeit zusammen. Besocders charakteristisch ist das Verhalten dieser Verbindung zu konzentrierter Schwefelsäure. Die Substanz löst sich dariu schon in der Kälte zu einer rehbraunen Flüssigkeit. Erwärmt man aber 
hierauf vorsichtig bis zum beginnenden Farbenwechsel, so nimmt dieselbe alsbald eine schön ziegel- bis fleischrote Färbung an, welche beim Stehen dann weiterhin - besonders am Rande - in karminrot übergeht! Versetzt man nun die Flüssigkeit vorsichtig und tropfenweise mit Wasser, so scheidet sich ein hochkarminroter Niederschlag ans, welcher auf Zugabe von mehr Wasser wieder verschwindet. Die derart resultierende Lösung ist farblos. Der vorliegende Körper stimmt sonach in seinem Verhalten zu konzentrierter Schwefelsăure durchaus mit dem von Tiemann und $W^{1}{ }^{1}{ }^{1}$ ) aus der Isoferulasäure gewonnenen, als Hesperetol bezeichneten Vinyl-p-Methoxy-Brenzkatechin, wie auch mit dem von mir vor einer Reihe von Jahren aus der Dioxyzimtsäure (Kaffeesäure) durch Kohlensäureabspaltung dargestellten und beschriebenen Vinyl-Brenzkatechin ${ }^{2}$ ) überein!

$\mathrm{Da}$ nun aber das Fabianaresen augenscheinlich in engen Beziehungen zu den von Tschirch und dessen Schülern als integrierende Bestandteile gewisser Harze nachgewiesenen Resenen steht, so würde diese Reaktion, falls dieselbe auch bei diesen letztgenannten Körpern zutreffen sollte, insofern allgemeineres Interesse beanspruchen dürfen, als in derselben vielleicht eine direkte Andeutung hinsichtlich der Konstitution dieser bekanntlich so schwer zugänglichen Pflanzenstoffe gewonnen wăre.

Wird die Lösung des Fabianaresens in konzentrierter Schwefelsăure längere Zeit auf dem siedenden Wasserbade erhitzt, so geht die zunächst ziegelrote Farbe desselben in schokoladebraun über. Beim Eingiessen dieser Lösung in viel Wasser scheidet sich ein graues, amorphes Reaktionsprodukt aus, welches sich beim Erwärmen der Flüssigkeit zu einem grauschwarzen Harze zusammenballt. Das Filtrat von diesem ist im durchfallenden Lichte gelbbraun gefärbt und zeigt grüne Fluorescenz. Irgend welche greifbare Verbindungen konnten bisher nicht isoliert werden.

Neben dem Fabianaresen wurden geringe Mengen einer gelblichen, in Wasser und Alkohol löslichen Substanz erhalten. Von Ammoniak und ebenso von verdünnter Salpetersăure wird dieselbe mit goldgelber Farbe gelöst. Der nach dem Verdunsten der letzeren Lösung auf dem Wasserbade hinterbleibende Rückstand ist in Ammoniak mit gelbbranner Farbe löslich (Unterschied von der Chrysatropasänre). Die wässerige Lösung ist gelb gefärbt, fluoresciert nicht und wird durch Ferrichlorid grün, auf Zusatz von Natriumkarbonat rot gefärbt. In der wässerigen Lösung entsteht durch neutrales Bleiacetat und Ammoniak ein gelber

1) Ber. d. Deutsch. chem. Ges. 14 (1881), p. 967.

2) Arch. d. Pharm. 231 (1893), p. 634. 
Niederschlag. Aus der mit Tierkohle behandelten Lösung in verdünntem Alkohol hinterbleibt der Körper bei langsamem Verdunstenlassen in Form teiner, schwefelgelber, konzentrisch gruppierter Prismen, bezw. in Form breiter, meist kreuzförmig über einander gelagerter, charakteristischer Wetzsteinformen. Eine năhere Untersuchung dieses Körpers musste wegen des in zu geringer Menge zur Verfügung stehenden Materials zanächst unterbleiben.

Die durch Extraktion mit Chloroform vom Fabianaresen, Fett, Wachs und von der Chrysatropasäure befreiten Blätter wurden - zur Gewinnung der Fabianagerbsäure - dreimal mit Wasser ausgekocht und die auf dem Wasserbade zum Extrakt eingedampften Auszüge zunächst durch Alkohol von den Pectinsubstanzen befreit. Das resultierende, goldgelbe Filtrat wurde hierauf auf dem Wasserbade eingedunstet und der extraktförmige Rückstand von neuem mit starkem Alkohol aufgenommen. Es bildet sich ein hellgelber, zunächst noch etwas klebender Niederschlag, welcher aber beim Stehen unter absolutem Alkohol fest wird und sich nun zu einer hellgelben, körnigpulverigen Masse verreiben lässt. Diese letztere ist aber eine in die Gruppe der Glykotannoide gehörende Gerbsäure: das FabianaGlyk otannoid.

Durch mehrmals wiederholtes Lösen in wenig Wasser und Fällen mit absolutem Alkohol lässt sich dasselbe rein und auch aschefrei gewinnen und stellt alsdann ein hellgelbes, äusserst hygroskopisches, in Wasser und auch in verdünntem Alkohol leicht, in absolutem Alkohol schwer, in Aether nicht lösliches Pulver dar. Die Alkoholbehandlung muss - zur Entfernung der letzten Spuren Chrysatropasäure - solange fortgesest werden, bis die wässerige Lösung einer Probe des Tannoids auf Zusatz von Ammoniak keine Fluorescenz mehr annimmt.

$\mathrm{Zu}$ der Auffassung dieser Verbindung als eines Glykotannoids berechtigt das dieselbe charakterisierende Gesamtverhalten. Die wässerige Lösung ist von schwach saurer Reaktion.

Silbernitrat erzeugt in der konzentrierten wässerigen Lösung und in der Kälte einen gelblich-weissen, flockigen, in mehr Wasser und - infolge der frei werdenden Salpetersäure - auch in einem Ueberschuss des Fällungsmittels leicht löslichen Niederschlag. Nach kurzer Zeit tritt jedoch - beim Erwärmen oder nach Zugabe von Ammoniak sofort - und zwar in den verdünnten, wie konzentrierten Lösungen Reduktion unter Spiegelbildung ein. Dieselbe kommt als Zonenreaktion besonders gut zur Anschauung, wenn man die den Niederschlag verteilt enthaltende Flüssigkeit mit Ammoniak überschichtet. Es tritt dann an der Berührungsfläche der beiden Flüssigkeiten eine dunkel-purpurrote, dann schwarze Zone auf. 
Ferrichlorid erzeugt in den verdünnten wässerigen Lösungen des Körpers eine russisch-grüne Färbung, welche auf Zusatz von Natriumcarbonat in blutrot übergeht. Diese alkalische Lösung eignet sich besonders auch zur Prüfung des Tannoids auf etwa noch vorhandene Chrysatropasäure. Bei Abwesenheit dieser letzteren erscheint die alkalische Lösung im reflektierten Lichte intensiv schwarz und nicht fluorescierend, während bei Gegenwart von nur Spuren der genannten Verbindung eine intensiv indigblaue Fluorescenz auftritt.

Alkalische Kupferlösung wird von dem Tannoid beim Erwärmen kräftig reduziert.

Im Schmelzpunktrohr erwärmt, sintert die feingepulverte, über Schwefelsäure getrocknete Substanz bei $80^{\circ}$ zusammen, bläht sich dann zwischen $10^{\prime}$ )- $110^{\circ}$ - in Mittel bei $105^{\circ}$ - etwas auf, um bei $180-200^{\circ}$ das Mehrfache des ursprünglichen Volumens einzunehmen. Der Rückstand löst sich in Alkalien - wie das nicht erhitzte Tannoid mit gelber Farbe zu einer nicht fluorescierenden Flüssigkeit auf. Auch in konzentrierter Schwefelsäure ist derselbe löslich; aber es tritt weder direkt, noch nach dem Versetzen mit Wasser - wodurch ein Niederschlag entsteht - irgend welche charakteristische Färbung ein.

Ganz dasselbe Verhalten zeigt auch die Maté- bezw. Kaffeegerbsäure!

Das auf $100-110^{\circ}$ erhitzte Fabianaglykotannoid unterscheidet sich von dem nicht erhitzten durch sein Verhalten gegen Ferrichlorid. Während die in der wässerigen Lösung des letzteren durch Ferrichlorid zunächst erzeugte gelbe Fïrbung alsbald in grün, grünbraun und endlich in braun übergeht, hält sich die mit dem erhitzten Tannoid ebenfalls entstehende Gelbfärbung selbst bei mehrtägigem Stehen an der Luft unverändert. Hieraus geht hervor, dass bereits bei $105^{\circ}$ eine tiefgreifende Veränderung des Fabianaglykotannoids stattfindet.

Diese $Y$ ersuche führten zur Beobachtung eines weiteren eigentümlichen Verhaltens dieses Körpers: leicht eine Jodoform liefernde Gruppe abzuspalten. Bei der Destillation der mit Kalilauge versetzten, wässerigen I ösung wurde ein Destillat erhalten, welches beim Erwärmen mit Kalilange und Jod-Jodkalium eine reichliche Abscheidung von Jodoform lieferte. Das gleiche Resultat wurde erzielt, als das 'Tannoid im Schwefelsäurebade auf $165^{\circ}$ erhitzt wurde, wobei ein trockener Luftstrom die Reaktionsprodukte in eine alkalische Lösung von Jod-Jodkalium überführte. Schon nach kurzer Zeit begann in dieser letzteren die Abscheidung der charakteristischen, sechsseitigen Blättchen des Jodoforms. Die Abspaltung der Jodoform liefernden Gruppe ist nebenher von der Bildung saurer Produkte begleitet: 
die im Ableitungsrohr kondensierte Flässigkeit zeigte stark saure Reaktion.

Die quantitative Prüfung dieser Reaktion ergab folgende Werte:

0,6797 des über Schwefelsäure bis zum konstanten Gewicht getrockneten Tannoids verloren beim Erhitzen auf $165^{0}: 0,1020 \mathrm{~g}=15,00 \%$.

$\mathrm{Ob}$ dieses Verhalten auf die Gegenwart von Methoxylgruppen im Molekül des Fabianaglykotannoids zurückzuführen ist, oder aber durch von diesem letzteren bei der Darstellung aufgenommenen und sehr fest gebundenen Alkohol bedingt wird, ist zur Zeit noch unentschieden.

Als Rückstand hinterbleibt ein hellbraunes, amorphes, in Wasser leicht lösliches Pulver, welches aber - zum Unterschied von dem Tannoid - nicht mehr hygroskopisch ist. Ferrichlorid erzeugt in der wässrigen Lösung einen schwarz-gränen Niederschlag. Gleichzeitig findet aber auch partielle Reduktion des Ferrichlorids statt, denn das Filtrat vom Niederschlage giebt mit Ferricyankalium starke Eisenoxydulreaktion.

Dieses anderenorts ${ }^{1}$ ) noch näher zu beleuchtende Verhalten gebietet aber - fïr alle nicht krystallisierenden Tannoide - bei der Aufstellang von Formeln auf Grund der elementaranalytischen Werte die grösste Vorsicht! Ich gebe daher auch die nachstehenden Werte unter dem Vorbehalt weiterer Prüfung.

$0,3662 \mathrm{~g}$ der über Schwefelsäure bis zum konstanten Gewicht getrockneten Substanz lieferten bei der Verbrennung mit Kupferoxyd im Sanerstoffstrom:

$$
\begin{aligned}
& 0,5681 \mathrm{~g} \mathrm{CO}_{2}=42,299 \% \mathrm{C} \text { und } \\
& 0,1865, \mathrm{H}_{2} \mathrm{O}=5,65 \% \mathrm{H} \text {. }
\end{aligned}
$$

Auf Zusatz von Kali-, bezw. Natronlauge, wie von Ammoniak nimmt die wässerige Lösung des Tannoids eine intensiv goldgelbe Farbe an, welche aber - zum Unterschied von der Kaffee-, bezw. Matégerbsäure - gegen den Luftsanerstoff, wie gegen Oxydationsmittel, z. B. Wasserstoffsuperoxyd, beständig ist, d. h. nicht in gr ün, bezw. braun umschlägt. ${ }^{2}$ )

Wird die wässerige Lösung des Tannoids mit konzentrierter Kalilauge zum Sieden erhitzt, so verschwindet nach einiger Zeit die goldgelbe Färbung und die Flüssigkeit färbt sich braunschwarz. In verdünnte Schwefelsäure eingegossen, entsteht ein schwarzbrauner Niederschlag. Der Flissigkeit entzieht Aether einen in Wasser sehr leicht löslichen Körper. Die wässerige Lösung reagiert stark sauer, reduziert

1) S. Pharm. Zentralh. 1898.

2) S. H. Kunz-Krause, Arch. d. Pharm. 236 (1898), pag. 568. 
ammoniakalische Silbernitratlösung bereits in der Kälte und liefert mit neutralem, wie auch ammoniakalischem Bleiacetat gelbe Niederschläge.

$0,2411 \mathrm{~g}$ des über Schwefelsäure bis zum konstanten Gewicht getrockneten Bleisalzes lieferten beim Abrauchen mit Schwefelsäure:

$$
0,1632 \mathrm{~g} \mathrm{~Pb} \mathrm{SO}_{4}=46,24 \% \mathrm{~Pb} \text {. }
$$

Ferrichlorid erzeugt Grünfärbung der wässerigen Lösung, welche auf Zusatz von Natriumkarbonat in rotviolett übergeht. Mit Bromwasser entsteht - wie bei der Kaffeesäure - erst beim Erhitzen ein gelber Niederschlag eines Bromderivates. Durch Uebersättigen mit Ammoniak entsteht in der wässerigen Lösung der Säure keine Fluorescenz. Bei freiwilligem Verdunsten hinterlässt die wässerige Lösung Prismen.

Baryumhydroxyd und ebenso Bleiacetat erzeugen in der wăsserigen Lösung des Fabianaglykotannoids amorphe, schön hochgelb gefärbte Niederschläge. Dieselben sind in kaltem, wie in warmem Wasser unlöslich, leicht löslich hingegen in verdünnten, selbst organischen Säuren und in Alkalien. Das für die nachstehende Bleibestimmung verwendete Bleisalz wurde durch Fällen der alkoholischätherischen Lösung des Fabianaglykotannoids mit einer alkoholischen Lösung von Bleiacetat dargestellt. Dasselbe stellte ebenfalls ein hoch gelbes, amorphes Pulver dar. lieferten:

$0,2821 \mathrm{~g}$ der bei $105^{\circ}$ bis zur Gewichtskonstanz getrockneten Verbindung

$$
0,1431 \mathrm{~g} \mathrm{~Pb} \mathrm{SO}_{4}=34,63 \% \mathrm{~Pb} \text {. }
$$

Da nun - wie ich anderenorts eingehender darlegen werde - alle gelbgefärbten Bleisalze von Tannoiden basische Salze zu sein scheinen, so würde sich aus diesem Bleigehalte das Aequivalentgewicht des freien Fabianaglykotannoids nach der Gleichung: $34,63: 100=2 \mathrm{~Pb}(412,8): \mathrm{x}$ für die wasserfreie Substanz zu 391,6, bezw. unter Hinzurechnung von $\mathrm{H}_{\mathbf{2}} \mathrm{O}$ zu 409,6 berechnen. Diesem letzteren Werte würde aber eine Verbindung von der Zusammensetzung:

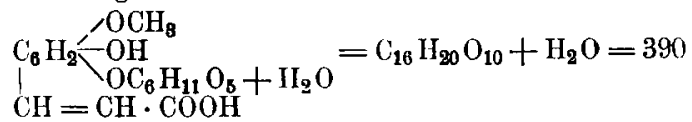

nahekommen, deren basisches Bleisalz:

$$
\begin{aligned}
& \mathrm{C}_{6} \mathrm{H}_{2}-\underset{\mathrm{OC}}{\mathrm{OCH}}-\stackrel{\mathrm{CH}_{6}}{\mathrm{H}_{11} \mathrm{O}_{5}}-\mathrm{Pb}-\mathrm{C}_{6} \mathrm{H}_{11} \mathrm{O}_{5} \mathrm{O} / \\
& \mathrm{CH}=\mathrm{CH} \cdot \mathrm{COO}-\mathrm{Pb}-\mathrm{OOC} \cdot \mathrm{CH}=\mathrm{CH}
\end{aligned}
$$

im Bleigehalte dem oben gefundenen Werte entsprechen würde:

$$
\begin{array}{cc}
\text { Gefunden: } & \text { Berechnet für } \mathrm{C}_{82} \mathrm{H}_{88} \mathrm{O}_{20} \mathrm{~Pb}_{\mathbf{2}}+2 \mathrm{H}_{2} \mathrm{O} \text { : } \\
\text { Proz. } \mathrm{Pb} \quad 34,63 & 32 .
\end{array}
$$


a koholischen Lösung von neutralem Kupferacetat oder aber einfach durch Vermischen der betreffenden wässerigen Lösungen - diargestellt. Das Silz bildet nach dem Trocknen ein olivgrünes Pulver, welches ohne Zersetzung zu erleiden, bei $105^{\circ}$ getrocknet werden kann.

$0.2395 \mathrm{~g}$ der bei $105^{\circ}$ bis zur Gewichtskonstanz getrockneten Verbindung ergaben nach dem Verglühen mit Quecksilberoxyd

$$
0,0413 \mathrm{~g} \mathrm{CuO}=13,73 \% \mathrm{Cu} \text {. }
$$

Aus diesem Kupfergehalte würde sich aber das Aequivalentgewicht des freien Fabianaglykotannoids nach der Gleichung: $13,73: 100=2 \mathrm{Cu}(127): x$ für die wasserfreie Substanz zu 400,99, bezw. unter Hinzurechnung von $\mathrm{H}_{2} \mathrm{O}$ zu 418,99 berechnen. Auch dieser Wert würde demnach der oben mitgeteilten Formel nahekommen, deren basisches, dem obigen Bleisalz gleich zusammengesetztes Kupfersalz:

$$
\begin{aligned}
& \mathrm{C}_{8} \mathrm{H}_{2} \underset{\mathrm{CH}=\mathrm{OC}_{6} \mathrm{H}_{11} \mathrm{O}_{5}}{\mathrm{OCH} \cdot \mathrm{COO}} \mathrm{Cu}-\stackrel{\mathrm{CH}_{8} \mathrm{H}_{11} \mathrm{O}_{5} \mathrm{O}}{\mathrm{O}}-\mathrm{OOC} \cdot \mathrm{CH}=\mathrm{CH}
\end{aligned}
$$

im Kupfergehalte ebenfalls dem oben gefundenen Kupferwerte entsprechen würde:

$$
\begin{array}{cc}
\text { Gefunden: } & \text { Berechnet für } \mathrm{C}_{82} \mathrm{H}_{86} \mathrm{O}_{20} \mathrm{Cu}_{2}+2 \mathrm{H}_{2} \mathrm{O} \text { : } \\
\text { Proz. } \mathrm{Cu} & 13,73
\end{array}
$$

Bromwasser erzengt in der wässerigen Lösung des Fabianaglykotannoids sofort einen hellorangegelben Niederschlag. Derselbe wurde nach dem Auswaschen mit Wasser über Schwefelsäure getrocknet.

0,2896 $\mathrm{g}$ des über Schwefelsäure bis zur Gewichtskonstanz getrockneten Bromderivates lieferten bei der Brombestimmung nach Carius:

$$
0,2798 \mathrm{~g} \mathrm{Ag} \mathrm{Br}=41,11 \% \mathrm{Br} \text {. }
$$

Diese Zahlen stimmen aber annähernd auf eine Dibrom-MethoxyDioxyzimtsäure:

welche $43,47 \%$ Br verlangt.<smiles>CO[C@H](O)c1ccccc1Br</smiles>

Aus dem Filtrat vom Bromniederschlage konnte in der früher beschriebenen Weise ${ }^{1}$ ) der unter der Einwirkung des Broms aus dem Fabianaglykotannoid abgespaltene Zncker isoliert werden. Derselbe stellt einen zunächst noch als krystallisationsunfăhig zu bezeichnenden, Fehling'sche Lösung bei gelindem Erwärmen schon kraftig re-

1) Beiträge zur Kenntnis der Ilex paraguayensis und ihrer chemischen Bestandteile. Arch. d. Pharm. 231 (1893), pag. 639. 
duzierenden Sirup dar. Das Fabianaglykotannoid stimmt sonach in seinem Verhalten zu Brom mit der friher von mir nach dieser Richtung untersuchten Kaffee- bezw. Mategrerbsäure überein.

Die voraussichtlich als Spaltungsprodukt auftretende Methoxy Dioxyzimtsäure würde das Vorkommen des Anhydrides (Lactons) dieser letzteren, der Chrysatropasäure, in der Fabiana imbricata verstiandlich machen. Die Entstehung dieser letzteren aus dem Fabianaglykotannoid lässt sich vielleirht damit erklären, dass dieselbe durch eine intramolekulare hydrolytische Abspaltung des Zuckerrestes uuter Inanspruchnahme der Karboxylgruppe erfolgt:

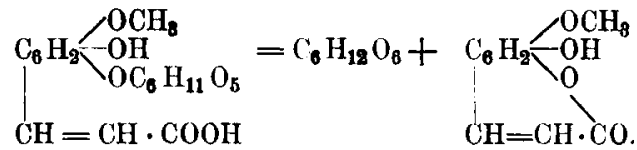

Andererseits möchte ich nicht verfehlen, darauf hinzuweisen, dass der nur schwach saure Charakter aller dieser Tannoide die Existenz von Karboxylgruppen in den Molekülen dieser Verbindungen ïberhaupt fraglich erscheinen lässt.

Metallisches Natrium erzeugt in der alkoholischen Lösung des Fabianaglykotannoids einen gelben, amorphen, ausserst hygroskopischen Niederschlag einer Natriumverbindung ${ }^{1}$ ). Versetzt man die wässerige Lösung des Tannoids unter Abkihhlen tropfenweise mit Li e b erm ann 'schem Reagens, so entsteht alsbald ein hellbraungelber, amorpher Niederschlag und nach einigen Tagen enthält die Flüssigkeit beträchtliche Mengen Blausäure, welche bereits durch den Geruch erkannt und in der früher ausführlich mitgeteilten $W$ eise ${ }^{2}$ ) nachgewiesen werden kann.

Benzoylchlorid erzeugt in der Lösung des Tannoids in 10 ${ }_{0}^{\circ}$ iger Natronlauge - nach der Methode von Baumann und Udránsky -einen gelblich-weissen, unlöslichen Niederschlag eines Benzoylderivates. Das gleiche Verhalten zeigt auch die sog. Kaffee- oder Matigerbsäure.

Das Fabianaglykotannoid stimmt sonach auch in seinem Verhalten zu Lieburuann's Reagens, wie zu Benzoylchlorid mit der als Matéoder Kaffegerbsäure bezeichneten Glyk os y l-Di o x y z i m ts süu re äberein.

Die in der vorliegenden Abhandlung mitgeteilten Untersuchungsresultate lassen sich kurz in folgendem zusammenfassen:

I. Fabiana imbricata enthält ausser dem im Holze und in den Blättern vorkommenden Cholin kein spezifisches Alkaloid; dafür aber

II. Eine Anzahl stickstofffreier, charakteristischer Pflanzenstoffe, und $z w a r:$

1) Arch. d. Pharm. 236 (1898), pag. 568.

2) Arch. d. Pharm. 231 (1893), pag. 633. 
a) Fabianol, und als dessen Oxydationsprodukt:

b) Fabianaresen.

c) Fabianaglykotannoid, und als voraussichtliche weitere Spaltungsprodukte desselben:

d) 4-Oxy -, 5-Methoxycumarol (Chrysatropasäure) und

e) einen nicht krystallisierenden und nicht drehenden, aber reduzierenden Zucker,

f) ein charakteristisches Weichharz, welches mit einem hohen Grad von Wahrscheinlichkeit direkt oder indirekt als die Muttersubstanz der vorgenannten Korper anzusehen ist. Die Entstehung dieser letzteren aus dem Weichharz lässt sich durch das Schema:

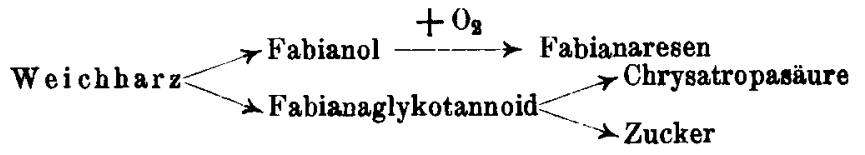
interpretieren.

Ш. Die Blätter der Fabiana imbricata sind reich an Magnesium. phosphat.

Lausanne, im September 1898.

\section{Arbeiten aus dem pharmazeutischen Institute der Universitat Bern.}

\section{Untersuchungen uber die Selkrete. \\ Von A. Tschirch.}

\section{Studien uber den Stocklack.}

Von A. Farner.

(Eingegangen den 5. XII. 1898.)

\section{A. Einleitung.}

„Der Schellack gehŏrt zu den Substanzen, mit welchen wir fast täglich in Berührung kommen und um welche sich doch niemand zu kümmern scheint ${ }^{u}$, schreibt Witt ${ }^{1}$ ), und mit Recht; denn obschon Schellack den Hauptbestandteil des Siegellackes bildet, obschon er in der Hutfabrikation und Feuerwerkerei, zar Politur von Holzgegenständen und zu Firnissen in Massen gebraucht wird, wissen wir noch heute über dessen chemische

1) Altes und Neues uber den Schellack, Prometheus 1896, pag. 209. 